\title{
CHAPTER 6
}

\section{Artificial Intelligence (AI) Based Tools for Predicting the Removal Efficiency of Heavy Metals by Adsorption

\author{
Nusrat Parveen ${ }^{1}$, Sadaf Zaidi ${ }^{2}$ and Mohammad Danish ${ }^{3}$ \\ Department of Chemical Engineering, Aligarh Muslim University, India \\ ${ }^{1}$ nusratalig@gmail.com, ${ }^{2 *}$ sadaf63in@yahoo.com and ${ }^{3}$ mohddanish.chem@gmail.com
}

\begin{abstract}
The two most popular artificial intelligence (AI) techniques namely, artificial neural networks (ANN) and support vector machines (SVM) have been applied for predicting the removal efficiency of heavy metals like Copper (II), Arsenic (III), Lead (II), etc. in an adsorption process using low cost biosorbents. A comparison has been made between ANN, SVM and multiple linear regression (MLR) models based on the statistical parameters such as: correlation coefficient (R), average absolute relative error (AARE) etc. SVM is found to be the better predictive model than the commonly used MLR model and ANN model. Hence, its results are more accurate and generalized.
\end{abstract}

Keywords

Artificial Intelligence (AI), Artificial Neural Networks (ANN), Support Vector Machines (SVM), Adsorption, Biosorption.

\section{Contents}

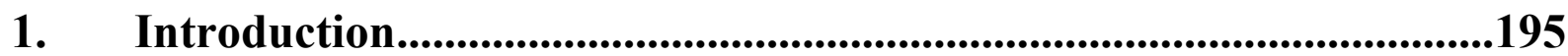

1.1 Adsorption ..............................................................................................196

2. An Overview of Artificial Intelligence (AI) Techniques ....................199

2.1 Artificial Neural Networks (ANN) ...........................................................199

2.2 Support Vector Machines (SVMs) .....................................................202

3. Application of AI Techniques .............................................................205

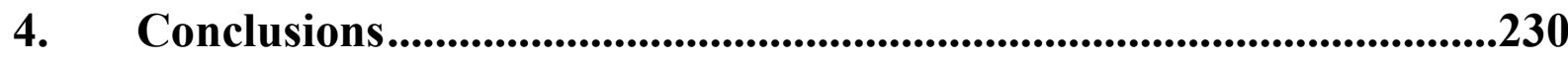




\section{Introduction}

Pollution due to heavy metals has become a major issue in many countries and this problem is becoming more serious every as the concentration of heavy metals is found to continually exceed the permissible standards. This is caused by heavy metals which are not biodegradable and toxic and thus are a great threat to the environment and human life. The major cause of increased heavy metals concentration in the environment is the effluents from many industries. Some of the prominent industries are: fuels related, fertilizer, iron and steel, leather, mining, petroleum refining etc. [1]. Most commonly found heavy metals in the effluents are: toxic metals (such as $\mathrm{Hg}, \mathrm{Cr}, \mathrm{Pb}, \mathrm{Zn}, \mathrm{Cu}, \mathrm{Ni}, \mathrm{Cd}$, $\mathrm{As}, \mathrm{Co}, \mathrm{Sn}$, etc.), precious metals (such as $\mathrm{Pd}, \mathrm{Pt}, \mathrm{Ag}, \mathrm{Au}, \mathrm{Ru}$ etc.) and radio nuclides such as U, Th, Ra, Am, etc. [2, 3]. These heavy metals are responsible for various serious health problems like brain damage, liver and kidney damage, break down of nervous system, lung cancer, bronchitis etc. Due to the severe impact of these metals on both environment and human health, removal and recovery of heavy metals from effluent streams is essential.

Several methods are being employed for the removal of these heavy metals coming from industrial effluents such as chemical precipitation, membrane filtration, ion exchange, activated carbon adsorption, evaporation etc. Recently, the biosorption process which is adsorption on a biosorbent has been found to offer an attractive substitute to these existing methods $[4,5]$. Besides being economical it has several advantages as compared to other conventional techniques such as high metal removal efficiency, minimization of chemical and toxic sludge or biological sludge which can be easily disposed of, minimum requirement of additional nutrients, easy regeneration of biosorbent and metal recovery $[6,7,3]$.

Biosorption of heavy metal removal is greatly affected by various parameters such as nature of biomass and its concentration, contact time between solution containing metal and the biomass, temperature, surface area to volume ratio, initial metal ion concentration, metal affinity to biosorbent and $\mathrm{pH}$ of the solution [8]. Heavy metal removal efficiency predictions are made by using several techniques like MLR, ANN, genetic algorithm (GA) etc. [9, 10, 11]. Recently, support vector machines (SVM) have been developed that are being applied for classification and regression termed as a support vector classification (SVC) and support vector regression (SVR). SVM possesses 
many advantages over traditional ANN. While ANN suffers from multiple local solution, SVM gives unique, optimal and global solution for quadratic problems. Only two parameters need to be selected, upper bound and kernel parameter. The use of a structural risk minimization (SRM) principle in SVM provides a good generalization performance. There are many past studies which show the superiority of SVM over ANN [12, 13, 14, $15]$.

SVR now finds many applications for the prediction of many real world problems like time series prediction, predicting thermal-hydraulic performances in compact heat exchangers, predicting the auto-ignition temperatures of the organic compounds, atmospheric temperature prediction, predicting heat transfer coefficient and circulation rate in a thermosiphon reboiler etc. [16, 17, 18, 19, 20, 21].

This chapter mainly focuses on the application of artificial intelligence tools, primarily SVR, to predict the removal efficiency of heavy metals during the adsorption process using low cost biosorbents. The first section of this chapter introduces the adsorption process as used for heavy metal removal from waste water. The second section discusses the basic principle and theory of the two most popular artificial intelligence techniques i.e. ANN and SVM. This is followed by a third section which presents three different case studies for the prediction of the removal efficiency of heavy metals: $\mathrm{Cu}$ (II), As (III) and $\mathrm{Pb}$ (II) using SVR for all the three cases and ANN for predicting the removal efficiency of $\mathrm{Pb}$ (II) only. Comparison of the results is made with the conventional MLR method. Further, for the case of $\mathrm{Pb}$ (II), the prediction performance of these three models is assessed in the light of existing theory and the experimental findings. The same along with the conclusions are presented in the last section.

\subsection{Adsorption}

Adsorption is essentially a surface phenomenon, the substance which gets adsorbed on to the surface is called adsorbate which may either be a liquid or gas on the other hand the surface usually a solid on to which this adsorbate gets adsorbed is referred as adsorbent. As adsorption being the surface phenomenon entirely different from absorption which is a bulk phenomenon, adsorbate permeates deeply into the adsorbent i.e. the whole volume of the material is involved in the absorption process. The term sorption includes both the process namely absorption and adsorption. The adsorption process is basically used to remove individual component from liquid or gas mixture. The component to be removed is physically or chemically bonded to a surface. Thus, adsorption may be categories into physical adsorption and chemical adsorption. 
Physical Adsorption or Physisorption

When the force of attraction between adsorbate and adsorbent is of the order of weak Vanderwaal force, the process is called physical adsorption or physisorption. In physisorption the enthalpy change is very low, typically $20-40 \mathrm{KJ} / \mathrm{mol}$. It takes place at low temperature and as the temperature increases, the physisorption process decreases.

\section{Chemical Adsorption or Chemisorption}

When the force of attraction between adsorbate and adsorbent is similar to those present in chemical bonding, the process is called chemical adsorption or chemisorptions. As compared to physisorption, the enthalpy change associated with chemisorptions is very high i.e. around $200-400 \mathrm{KJ} / \mathrm{mol}$. Chemisorption first increases with temperature and then decreases.

The major difference between physisorption and chemisorption include [22]:

- Physisorption is basically a reversible process and does not require any activation energy while chemisorption is an irreversible process and requires high activation energy.

- Chemisorption is highly selective and occurs only between certain active surface and adsorbent where as physisorption occurs on all surfaces if the conditions are favorable.

- Physisorption results in forming multimolecular layer while chemisorptions process proceeds in a monomolecular layer.

- Heat of adsorption for physisorption process is low on the other hand for chemisorption heat of adsorption is high.

The most commonly used industrial adsorbents are activated carbon, silica gel, molecular sieves, alumina, clay mineral and synthetic polymers etc. as they provide large surface areas per unit weight. A good adsorbent should have the following properties [23]:

- High porosity, high selectivity and large surface area per unit weight.

- Thermal, mechanical and chemical stability.

- Low pressure drop over the adsorber bed.

- Low fouling, no side reaction and easy regeneration.

- Low cost.

Applications of adsorption

Some of the important applications of adsorption are listed below [24, 25]: 
- Separation of gaseous mixture, chemicals and air.

- Purification of liquids and water, softening of hard water, removal of impurities from liquid and gas etc.

- Removal of coloring matter from solution.

- Volatile organic compound (VOCs) removal from the polluted air.

- Production of high vacuum.

- Using activated charcoal for the preparation of gas masks to avoid poisonous gases like $\mathrm{CO}, \mathrm{CH}_{4}$ etc.

- It plays a vital role in controlling the environmental pollution especially the control of 'greenhouse gases' like $\mathrm{CH}_{4}, \mathrm{CO}_{2}, \mathrm{~N}_{2} \mathrm{O}$ etc., thus, helps in reducing global warming.

Factors affecting the adsorption process

There are various factors which affect the adsorption process [26]:

- Nature of the adsorbent: The type of adsorbent used in the adsorption process plays an important role in the adsorption rate such as the chemical nature of adsorbent surface, its specific area and the extent of porosity. Since, adsorption is a surface phenomenon, the larger the surface area of the adsorbent, the larger is its capacity for adsorption.

- Temperature and Pressure: Adsorption is an exothermic process, therefore with the decrease in temperature, the rate of adsorption increases. Further adsorption of a gas is accompanied by decrease in pressure, the rate of adsorption increases as the pressure increases. Whereas decrease in pressure leads to desorption. Thus, the decrease in temperature and increase of pressure both leads to an increased rate of adsorption.

- Nature of the gas: The type of gases used also affects the adsorption process such as chlorine, sulphur dioxide and ammonia are more easily adsorbed because of weak Vander wall forces compared to oxygen, hydrogen and nitrogen. The rate of adsorption is in direct proportion to the critical temperature of gases and these gases have high critical temperature.

The amount of heavy metal removed during adsorption process is evaluated either in terms of adsorption capacity/metal uptake or heavy metal removal efficiency. In order to obtain the adsorption capacity, the amount of metal ions adsorbed per unit mass of adsorbent is determined using the following equation [27, 28]: 


$$
\mathrm{q}_{\mathrm{e}}=\frac{V\left(C_{o}-C_{f}\right)}{m}
$$

Where, $\mathrm{q}_{\mathrm{e}}, \mathrm{V}, \mathrm{m}, \mathrm{C}_{\mathrm{o}}$ and $\mathrm{C}_{\mathrm{f}}$ represent the metal ions adsorbed per adsorbent at equilibrium $(\mathrm{mg} / \mathrm{g})$, volume of solution (L), mass of adsorbent (g), the initial metal ions concentration in the solution $(\mathrm{mg} / \mathrm{L})$, final metal ions concentration in the solution $(\mathrm{mg} / \mathrm{L})$ respectively.

Heavy metal ion removal efficiency can be calculated with the amount of metal ions which gets adsorbed on the adsorbent and the available amount of metal ions in the solution as given by the equation below:

Heavy metal removal efficiency $(\%)=\frac{\text { Heavy metal ions removed }}{\text { Heavy metal ions remaining }} * 100$

\section{An Overview of Artificial Intelligence (AI) Techniques}

Artificial intelligence is the simulation of human intelligence processes by machines i.e. making the computer behave like humans. These processes include learning, reasoning, problem solving, perception, planning etc. Particular applications of AI include expert systems, speech recognition, and machine vision.

This section describes two very popular computational intelligence techniques namely, artificial neural networks (ANN) and support vector machines (SVMs).

\subsection{Artificial Neural Networks (ANN)}

Artificial neural networks are parallel processing computer algorithms inspired by the working of the human brain. The basic components of neural networks is composed of neurons and weights (bias). The neural networks architecture is made up of an input layer, one or more hidden layers and the output layer. The input layer receives the information and conveys this information/data to the hidden layer and does not carry any activation or transfer function. Hidden layers are sometimes called as "black boxes" as they are within the networks and no direct connection exists to the external environment [29]. The output layer processes the outcome of the hidden layer using some activation function [30] and then finally it sends the calculated output to the user. The most widely used activation functions are: linear function, piecewise linear function, tangent hyperbolic function, threshold function and sigmoidal ( $\mathrm{S}$ shaped) function. The neural networks structure can be of three types [31, 32, 33, 34, 35]: if the input layer is directly connected to the output then it is often called a single-layer network, and if some hidden layer exists between the input and the output layer then it is called a multi-layer network as shown in Figs. 1 and 2. A feed forward network with one or more hidden layers as well as with feedback loop is termed as a recurrent network i.e. output of the network is fed back to its input layer as shown in Fig 3. The number of neurons at the input and 
output layers is decided by the nature of the problem and the no. of neurons as the hidden layer is generally decided by the trial and error method. Too few neurons lead to an inadequately fit-to the data and problem of under fitting arises while too many neurons lead to an over fit-to the data and have poor generalizability [36].

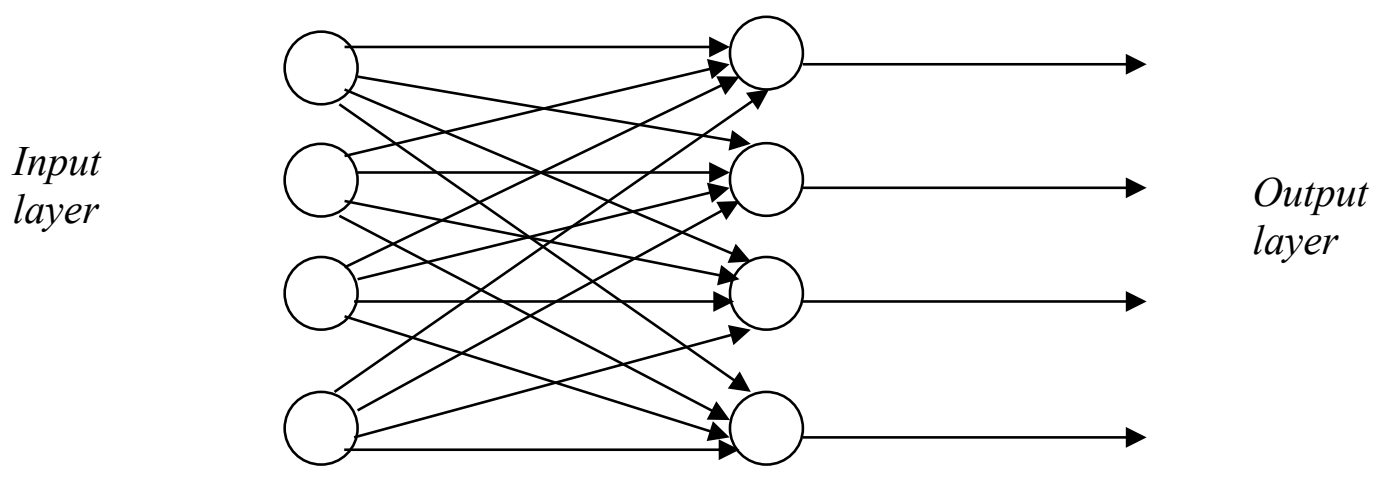

Figure 1. Single layer feed-forward NN (FFNN)

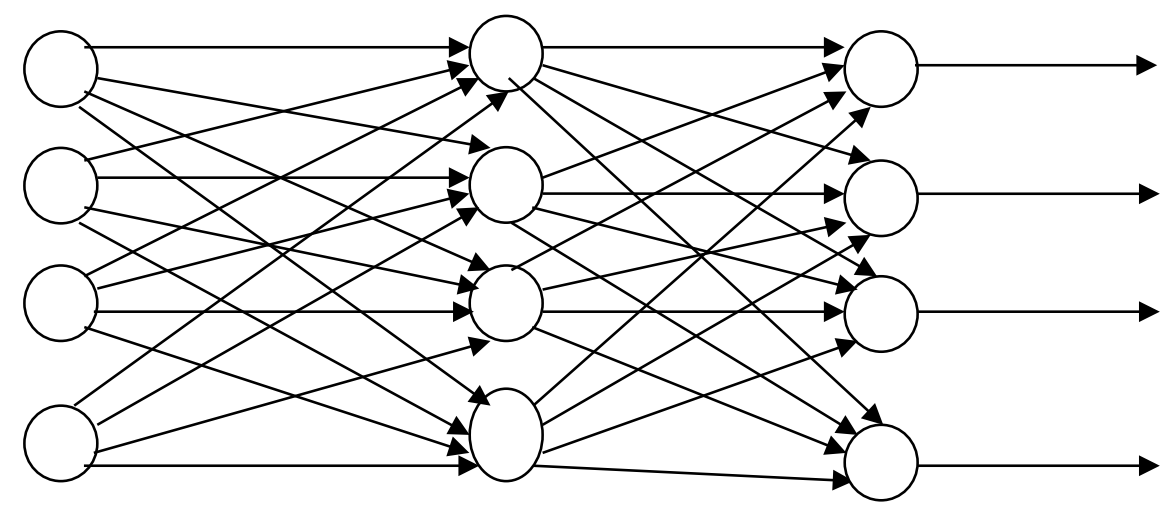

Input layer Hidden layer Output layer

Figure 2. Multi layer feed-forward NN (FFNN) 


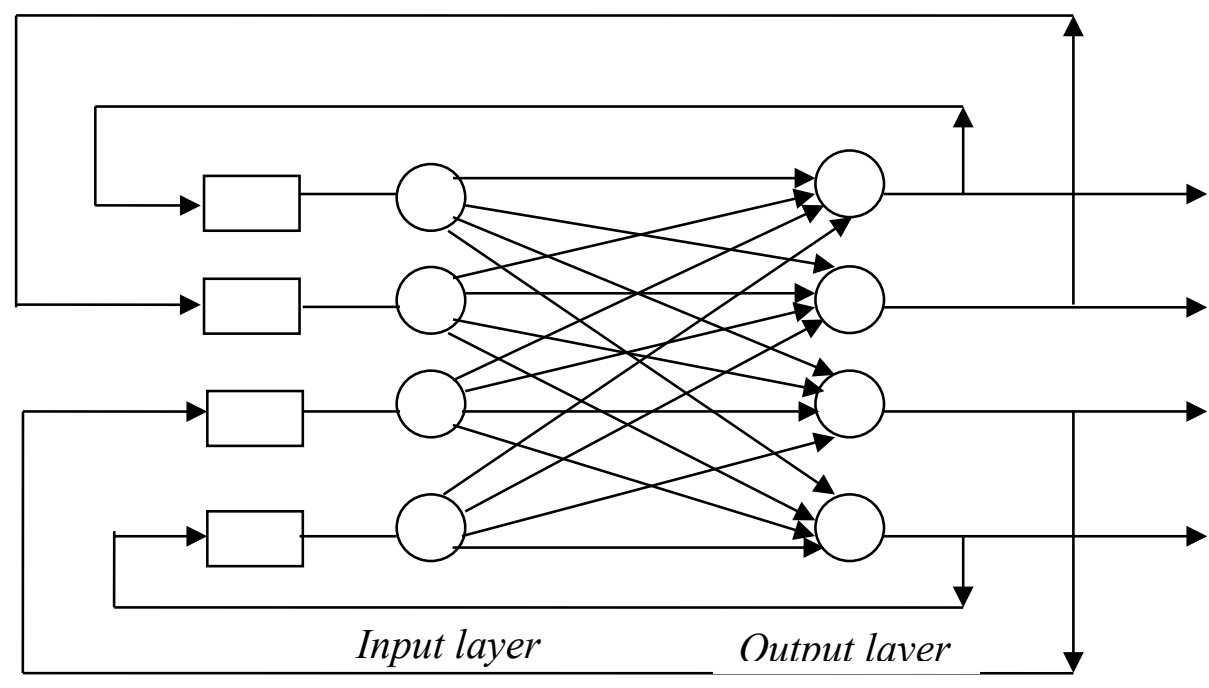

Figure 3. A recurrent network

\section{Neural learning}

Learning in neural networks basically refers to the method of modifying the weight of the connections between the nodes. Learning may be classified as supervised learning, unsupervised learning and reinforced learning. In supervised learning, the desired set of output (target) is available for each set of input. The weights of the connection are modified till the output of the response and target matches, otherwise the network produces an error. Whereas in unsupervised learning, no desired output (target) is available and the network adjusts its weight according to the input, and reinforced learning is in between the supervised and unsupervised learning. The desired output of the response is not compared with the target and it provides the information of the computed result, whether it is correct or not. Network weights are adjusted to have a good performance (based on certain criteria) and are rewarded while the other parts of ANN are penalized [37, 38].

The various steps involved for the development of ANN model are listed below [39, 40, 41, 42]:

1. Collection of data as input and output variables for a specified problem.

2. Data preprocessing i.e. scaling or normalization of data.

3. Dividing the whole data set into training, testing and validation sets. 
4. Selecting ANN architecture i.e. the type of ANN, no. of hidden layers, no. of neurons at the input layer, hidden layer and the output layer, type of activation function at the hidden layer and the output layer.

5. Neural networks training:

(a) A training set is used to adjust the weight and bias.

(b) A Validation set is used to check the generalization performance and when to stop the training process.

(c) A test set is used to check the performance of the developed ANN model based on some statistical parameters.

\subsection{Support Vector Machines (SVMs)}

Support vector machines (SVMs) are a set of related supervised learning methods [43, 44] originally developed for classification purposes i.e. support vector classification (SVC). However, it's application has now been extended to regression problems [45, 46, 47]. SVM is based on machine learning theory and enhances the accuracy of prediction while avoiding an over-fit to the data. Basically, SVM is superior than the conventional techniques like ANN on the following counts [48, 49, 12]: (a) only two parameters need to be selected i.e. upper bound and the kernel parameter, (b) unique, optimal and global solution for quadratic programming problem, and (c) implementation of structural risk minimization (SRM) principle provides good generalization performance [50]. Thus, SVM overcomes the problem of over fitting explicitly. Robustness of SVM is achieved by considering absolute, instead of quadratic values of the errors. As a consequence, the influence of outliers is less pronounced [51]. Because of these advantages, SVM has found many applications $[52,53]$.

\section{Theory and Basic Principles}

Fitting a regression function, $y=f(x)$ in a $\varepsilon$-SVR model is the basic goal so as to accurately predicts the targets $\left\{y_{i}\right\}$ corresponding to a set of input samples, $\left\{x_{i}\right\}$, With the given training data set as $\mathrm{D}=\left\{\left(x_{1}, y_{1}\right),\left(x_{2}, y_{2}\right), \ldots,\left(x_{N}, y_{N}\right)\right\}$, where $x_{i} \in R^{N}$ is a vector of input variables and $y_{i} \in R^{N}$ is the corresponding scalar output (target) value.

For the case of a linear function, SVR approximates the relationship between the output and input parameters given by:

$$
f(\mathbf{x}, \mathbf{w})=(\mathbf{w} \cdot \mathbf{x}+b)
$$

Where, $\mathbf{w}$ expresses the weight vector and $\mathbf{b}$ refers to a constant called bias. 
However, for non-linear problems of the real world where the input data cannot be correlated to the required output linearly, the following linear model can be constructed for high-dimensional feature space using a nonlinear mapping function $\phi(\mathbf{x})$ [54]:

$$
f(\mathbf{x}, \mathbf{w})=(\mathbf{w} \bullet \phi(\mathbf{x})+b)
$$

Where, $\phi(\mathbf{x})$ is the function termed feature and $(\mathbf{w} \bullet \phi(\mathbf{x}))$ the dot product in the feature space $\mathrm{F}$.

The regression problem is equivalent to minimizing the following regularized function:

Minimize: $\mathrm{R}(\mathrm{f})=C \frac{1}{N} \sum_{i=1}^{N} L_{\epsilon}(y, f(x, w))+\frac{1}{2}\left\|w^{2}\right\|$

$$
L_{\varepsilon}(y, f(\mathbf{x}, \mathbf{w}))=\left\{\begin{array}{cc}
0 & \text { if }|y-f(\mathbf{x}, \mathbf{w})| \leq \varepsilon \\
|y-f(\mathbf{x}, \mathbf{w})|-\varepsilon & \text { otherwise }
\end{array}\right.
$$

In Eq. (3), the first term represents the empirical error and the term $\mathrm{C}$ gives a measure of the trade-off between the training or empirical error and the model flatness given by the second term of the said equation. Eq. (4) defines the $\varepsilon$ - insensitive loss function proposed by Vapnik $[56,57]$. The loss function assumes a zero value in the $\varepsilon$-insensitive zone and as a result it does not penalize the prediction errors with magnitudes smaller than $\varepsilon$. However, practically it is not possible to establish a function, $f(\mathrm{x}, \mathrm{w})$ with errors less than $\varepsilon$. In that case, some allowance for errors has to be considered, which can be represented in terms of slack variables $\xi$ and $\xi^{*}$. These slack variables have non-zero values outside the $\varepsilon$-insensitive zone and measure the deviation from the boundaries of the $\varepsilon$-insensitive zone (penalty).

Thus after introducing the slack variables $\xi$ and $\xi^{*}$, SVR is formulated as minimization of the following convex optimization problem:

Minimize $\frac{1}{2}\left\|\mathbf{w}^{2}\right\|+C \sum_{i=1}^{N} \xi_{i}+\xi_{i}^{(*)}$

Subject to

$$
\begin{aligned}
& \left(y_{i}-\mathbf{w} \bullet \phi(\mathbf{x})-b\right) \leq \varepsilon+\xi_{i}, \\
& \left(\mathbf{w} \bullet \phi(\mathbf{x})+b-y_{i}\right) \leq \varepsilon+\xi_{i}^{(*)}, \xi_{i}, \xi_{i}^{*} \geq 0
\end{aligned}
$$

The above optimization problem can be transformed into a dual problem by incorporating Lagrangian multipliers $\alpha$ and $\alpha^{*}$ as follows:

Maximize 
$L_{d}\left(\alpha_{i, j}^{(*)}\right)=-\frac{1}{2} \sum_{i=1}^{N} \sum_{j=1}^{N}\left(\alpha_{i}-\alpha_{i}^{*}\right)\left(\alpha_{j}-\alpha_{j}^{*}\right) \times\left(\phi\left(\mathbf{x}_{i}\right) \bullet \phi\left(\mathbf{x}_{j}\right)\right)-\varepsilon \sum_{i=1}^{N}\left(\alpha_{i}-\alpha_{i}^{*}\right)-\sum_{i=1}^{N}\left(\alpha_{i}+\alpha_{i}^{*}\right) y_{i}$

Subject to constraints

$$
C \geq \alpha_{i}, \alpha_{i}^{*} \geq 0 \text { and } \sum_{i=1}^{N} y_{i}\left(\alpha_{i}-\alpha_{i}^{*}\right)=0
$$

By solving this convex quadratic programming problem (QP), the coefficients $\alpha$ and $\alpha^{*}$ in Eq. (8) are obtained. Only the non-zero coefficients, and the corresponding input vectors, $\mathbf{x}_{i}$, are called support vectors (SVs). These SVs are the most informative data points that compress the information content of the training set, thereby representing the entire SVR function.

The expanded form of the SVR is thus given as:

$$
f\left(\mathbf{x}, \alpha_{i}, \alpha_{i}^{*}\right)=\sum_{i=1}^{N_{s v}}\left(\alpha_{i}-\alpha_{i}^{*}\right)\left(\phi\left(\mathbf{x}_{i}\right) \bullet \phi\left(\mathbf{x}_{j}\right)\right)+b
$$

However, for the above-mentioned problem [Eq. (10)], the inner product in the feature space needs to be calculated. But with the increase in the input dimensions, the computation in the high-dimensional feature space becomes a computationally complicated problem (curse of dimensionality). Such a problem of contradiction between high dimensions and computational complexity can be overcome by using the kernel trick or defining appropriate kernel functions in place of the dot product of the input vectors in high-dimensional feature space. The kernel function is used to compute directly the inner product from the input space, rather than in the high dimensional feature space. Kernel functions provide a way to avoid the curse of dimensionality.

The most commonly used kernel functions include linear function, polynomial function, Gaussian function, and sigmoid function, spline, etc. [58]. The Gaussian function is a widely used kernel function as it can map the input space sample set into a high dimensional feature space effectively and is good for representing the complex nonlinear relationship between the input and output samples. Furthermore, only one variable (the width parameter) is there to be defined [21, 19]. Considering the above advantages, the Gaussian radial basis function (RBF) is chosen as the kernel function in this work and the expression is given as:

$\mathrm{K}\left(x, x_{i}\right)=\exp \left(-\frac{\left\|x-x_{i}\right\|^{2}}{\sigma^{2}}\right)$

Where, $\sigma$ denotes the width of the RBF and $\gamma=\frac{1}{2 \sigma^{2}}$ 
Thus by applying the kernel function, the basic SVR function modeling the data obtained by using the above-mentioned maximization function is then given by:

$f\left(\mathbf{x}, \alpha_{i}, \alpha_{i}^{*}\right)=\sum_{i=1}^{N_{\text {sv }}}\left(\alpha_{i}-\alpha_{i}^{*}\right) K\left(\mathbf{x}, \mathbf{x}_{i}\right)+b$

The bias parameter, $b$, can be obtained by applying Karush-Kuhn-Tucker (KKT) conditions.

SVR modeling procedure

The computational procedure for SVR modeling can be broadly divided into five stages $[59,60,61]$ :

1. The first step is to collect the data set as independent input variables and the target output variable.

2. Thereafter, the data set is normalized and then divided into a training data set and test data set in the ratio of $8: 2$.

3. Once the training data set is selected and normalized, the next step is to optimize the model and kernel parameters using grid search methodology with K-fold cross validation.

4. Establishment of final SVR model is carried out using the obtained optimal parameters.

5. The performance of the obtained SVR model is evaluated and validated in terms of the statistical evaluation parameters such as average absolute relative error (AARE), root mean square error (RMSE), coefficient of determination $\left(\mathrm{R}^{2}\right)$ etc., comparing the prediction performance with models existing in literature and in the light of existing theory.

\section{Application of AI Techniques}

The following sections discuss three case studies for the prediction of the removal efficiency for $\mathrm{Cu}$ (II), As (III) and lead (II) by applying AI techniques like ANN and SVM and the comparison of the results with MLR.

\section{CASE STUDY - I}

PREDICTION OF Cu (II) BIOSORPTION EFFICIENCY

In this study, an effort has been made to assess the performance of a developed SVRbased model for predicting the biosorption efficiency of $\mathrm{Cu}$ (II) ions on the litter of a 
natural trembling poplar (Populus tremula) forest (LNTPF) as a low-cost and abundant biosorbent vis-à-vis an MLR model using the same data set extracted from published literature [62].

\section{Analysis of the MLR model}

As per the existing theory, it has been found that the $\mathrm{Cu}(\mathrm{II})$ biosorption efficiency (\%) depends on $\mathrm{pH}\left(\mathrm{a}_{1}\right)$, temperature $\left(\mathrm{a}_{2}\right)$, particle size $\left(\mathrm{a}_{3}\right)$, agitating speed $\left(\mathrm{a}_{4}\right)$, initial $\mathrm{Cu}(\mathrm{II})$ concentration $\left(a_{5}\right)$, adsorbent concentration $\left(a_{6}\right)$, and the contact time $\left(a_{7}\right)$. The following MLR model equation has been obtained:

$\mathrm{y}=-8.3357+11.0513\left(\mathrm{a}_{1}\right)+0.3574\left(\mathrm{a}_{2}\right)-30.3253\left(\mathrm{a}_{3}\right)+0.0608\left(\mathrm{a}_{4}\right)-0.2541\left(\mathrm{a}_{5}\right)+$ $5.9614\left(\mathrm{a}_{6}\right)+0.06619\left(\mathrm{a}_{7}\right)$

The independent variables are found to be significant into the regression.

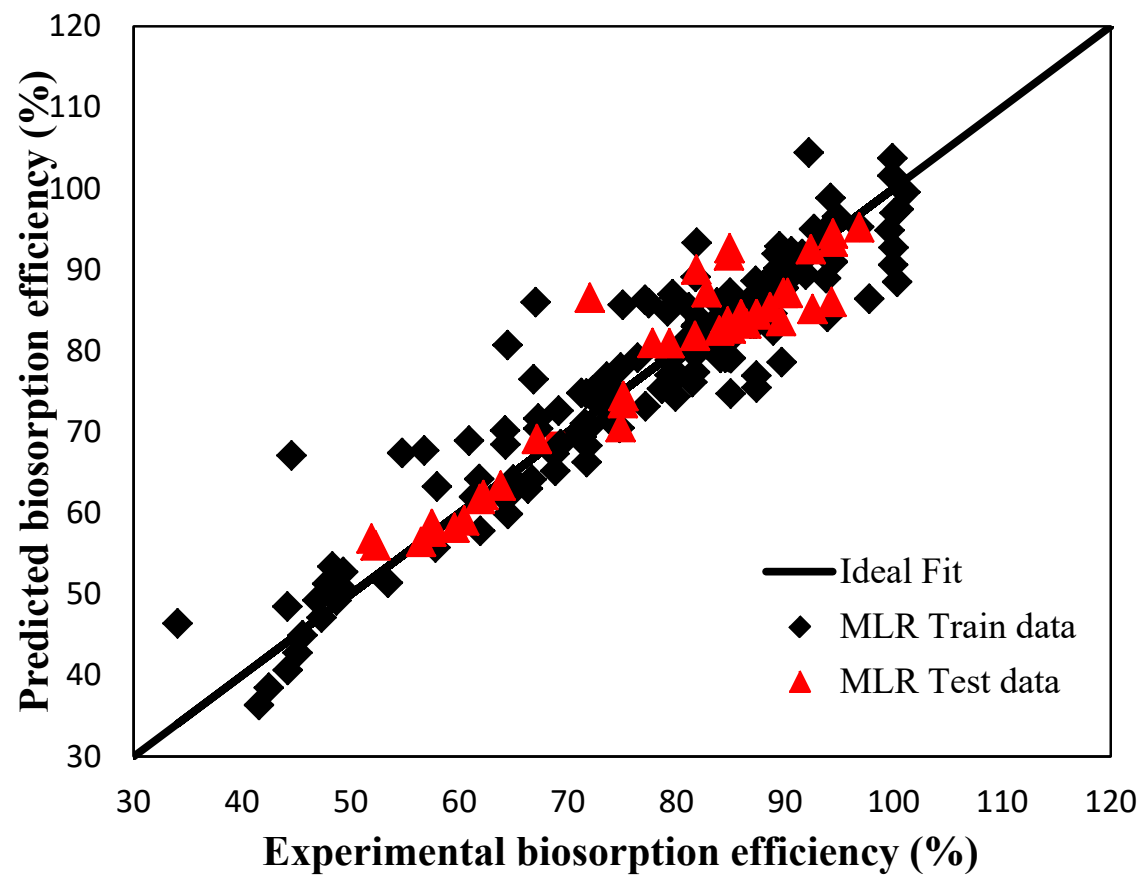

Figure 4. Performance of MLR model using training data and test data for prediction of $\mathrm{Cu}(\mathrm{II})$ biosorption efficiency (\%).

Performance assessment of the MLR model has been carried out based on statistical parameters namely, AARE, R2, RMSE, SD and MRE. A comparison between the predicted values of $\mathrm{Cu}(\mathrm{II})$ biosorption efficiency (\%) by the MLR model and those calculated from the experimental data using the training dataset and the test dataset is shown in the Fig. 4. An AARE of $5.514 \%$, R2 of 0.8708 , RMSE of 0.0733 , SD of 14.0785 and MRE of 0.0527 on the training data are obtained while the corresponding 
values for the test data are: $5.327 \%$ AARE, 0.8965 R2, 0.0665 RMSE, 12.94 SD and 0.0525 MRE. It can be seen that the MLR model has consistent prediction ability. In fact, the model gives an improved generalized performance on the test data set.

\section{Analysis of the SVR-based model}

The entire dataset of 197 samples is divided into two non-repetitive groups as the training dataset and the testing dataset using the simple random sampling (SRS) technique, in the ratio of 8 (158 data points): 2 (39 data points), respectively. Thereafter, using the same training data set, a SVR-implementation known as " $\varepsilon$-SVR" in the open software LIBSVM library [63] on MATLAB platform has been used to develop the SVR-based model. The generalization ability of the SVR model has been assessed using the virgin test data set.

RBF kernel has been used in this study because of its good general performance and the requirement of few parameters to be adjusted [58]. For achieving the optimal values of the SVR model hyper-parameters $(\mathrm{C}$ and $\varepsilon$ ) and the kernel parameter $(\gamma)$, grid search methodology with 10 -fold cross validation has been carried out on the training data set by considering a wide range of these parameters: $C\left[2^{5}, 2^{15}\right], \gamma\left[2^{-15}, 2^{2}\right]$ and $\varepsilon\left[2^{-15}, 2^{4}\right]$. The optimal values of the model parameters for the SVR model are given in Table 1.

Table 1. Optimal parameters for SVR-based model for Cu (II) biosorption efficiency in a biosorption Process.

\begin{tabular}{|c|c|c|c|c|c|c|c|}
\hline $\begin{array}{c}\text { Property to } \\
\text { be } \\
\text { predicted }\end{array}$ & $\mathrm{C}$ & $\begin{array}{c}\gamma \\
=1 / 2 \sigma^{2}\end{array}$ & $\varepsilon$ & $\begin{array}{c}\text { Kernel } \\
\text { type }\end{array}$ & $\begin{array}{c}\text { Type of } \\
\text { Loss } \\
\text { function }\end{array}$ & $\begin{array}{c}\text { Number } \\
\text { of support } \\
\text { vectors }\end{array}$ & $\begin{array}{c}\text { Number } \\
\text { of } \\
\text { training } \\
\text { points }\end{array}$ \\
\hline $\begin{array}{c}\text { Biosorption } \\
\text { efficiency }\end{array}$ & 32768 & 0.01195 & 0.0625 & RBF & $\begin{array}{c}\varepsilon- \\
\text { insensitive }\end{array}$ & 104 & 158 \\
\hline
\end{tabular}

After optimization of the SVR parameters, the model output for the training and test data has been plotted in Fig. 5. It is evident that both the predicted values for the training data as well as the test data lie close to the ideal fit line. Table 2 exhibits the model evaluation parameters of the SVR-based model for both the training data as well as the test data. The close proximity to each other of the model evaluation parameters for the training data and test data testify to the excellent prediction performance and also to the high generalization ability of the SVR-based model. 


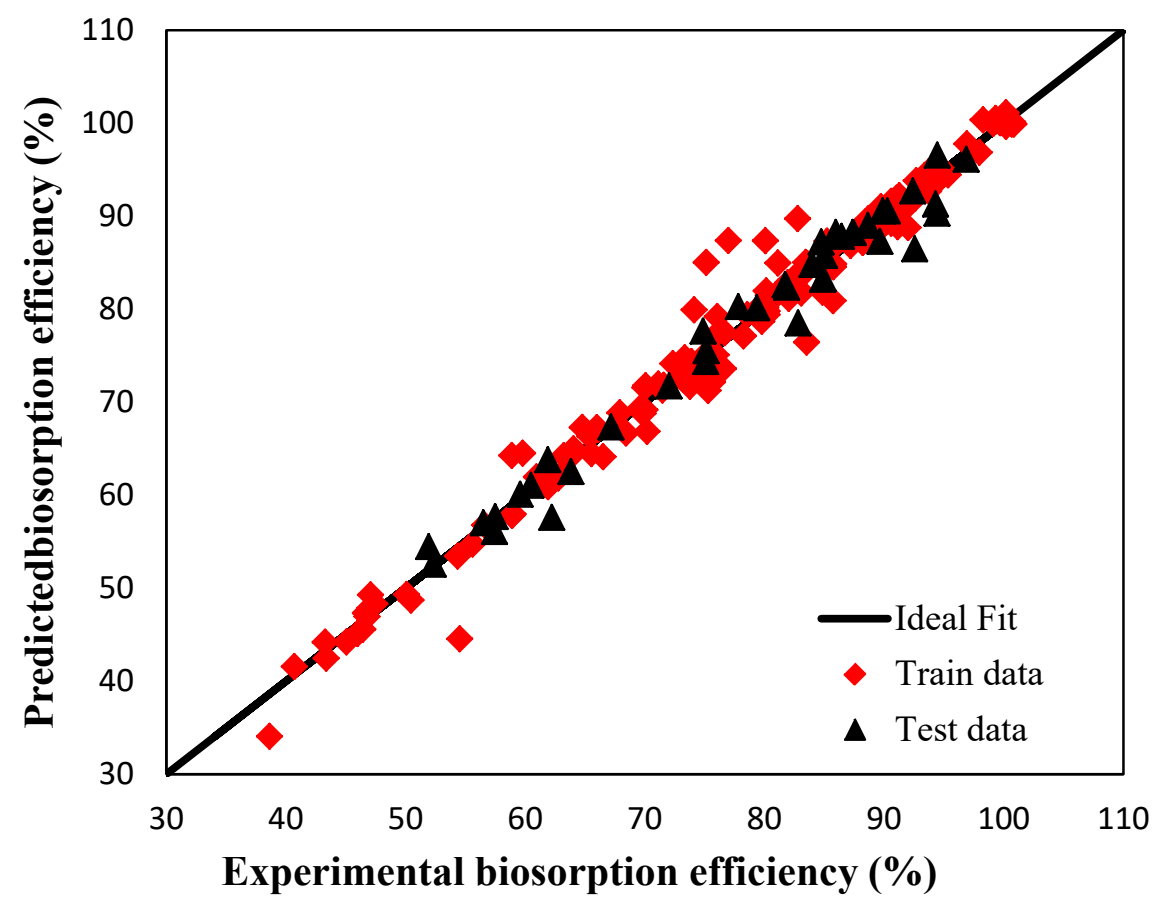

Figure 5. SVR simulation of Cu(II) biosorption efficiency(\%) in a biosorption process with optimal parameters using training data and test data.

Table 2. Model evaluation parameters for SVR-based model using the training data and the test data.

\begin{tabular}{|c|c|c|}
\hline SVR Model evaluation parameter & Train data & Test data \\
\hline AARE (\%) & 2.07 & 1.97 \\
\hline R & 0.9881 & 0.9879 \\
\hline RMSE & 0.0011 & 0.0007 \\
\hline SD & 14.837 & 13.2689 \\
\hline MRE & 0.0206 & 0.0199 \\
\hline$Q^{2}$ LOO (Train data), ${ }^{2}$ ext(Test data) & 0.9763 & 0.9759 \\
\hline
\end{tabular}

Comparison of SVR-based model with the MLR model.

A comparison was made of the prediction performances of the developed MLR model with the SVR-based model. Fig. 6 clearly illustrates the superior prediction performance of the SVR-based model. Table 3 exhibits the relevant model evaluation parameters for the two modeling methods on the test data set. It can be easily surmised that the SVRbased model is a vastly improved model than the MLR model. Further, in terms of 
absolute deviation (AD) values, the SVR-based model again scores over the MLR model as shown in Table 4 and 5.

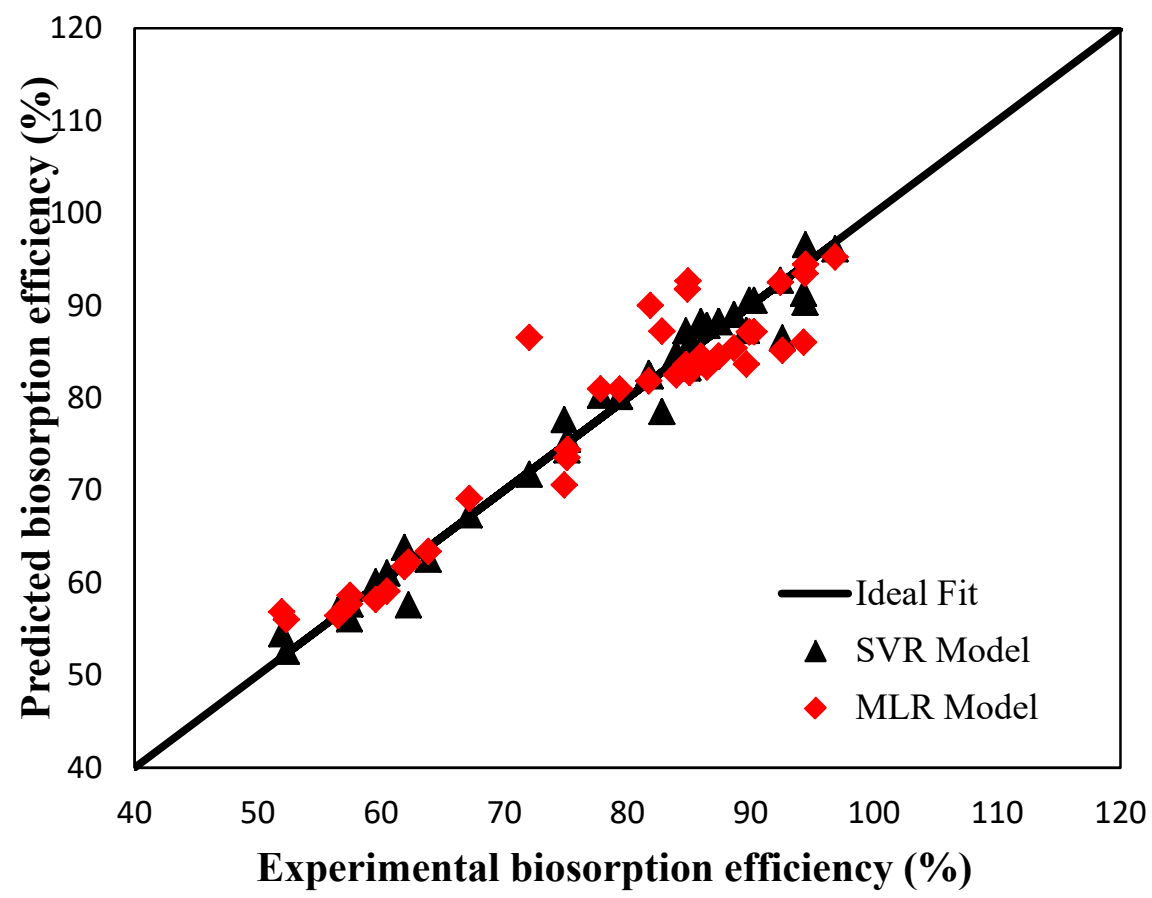

Figure 6. Comparison of SVR model with MLR model for prediction of Cu(II) biosorption efficiency (\%) in a biosorption process using test data.

Table 3. Model evaluation parameters for SVR-based model and MLR model using the test data.

\begin{tabular}{|c|c|c|}
\hline SVR Model evaluation parameter & SVR-based model & MLR model \\
\hline AARE (\%) & 1.97 & 5.33 \\
\hline $\mathrm{R}^{2}$ & 0.9760 & 0.8965 \\
\hline RMSE & 0.0007 & 0.0665 \\
\hline SD & 13.2689 & 12.9434 \\
\hline MRE & 0.01994 & 0.0525 \\
\hline
\end{tabular}

Table 4 illustrates the distribution of predicted data points of $\mathrm{Cu}$ (II) biosorption efficiency by the SVR-based model in terms of absolute deviation (AD) for the training data. The SVR-based model was found to predict nearly $92.4 \%$ data points within an absolute deviation of less than $5 \%$ and a total of $97.5 \%$ data points within an absolute deviation of less than $10 \%$. Only $2.5 \%$ data points have an AD of more than $10 \%$. Whereas, the MLR-based model was observed to predict only $65.1 \%$ data points within 
an absolute deviation of less than $5 \%$ and a total of $86.2 \%$ data points within an absolute deviation of less than $10 \%$. Only $13.8 \%$ data points have an AD of more than $10 \%$.

Table 5 depicts the distribution of predicted data points of $\mathrm{Cu}$ (II) biosorption efficiency by MLR and SVR-based model in terms of absolute deviation for the test data set. It is observed that the SVR based model predicts nearly $92.3 \%$ data points within an absolute deviation of less than $5 \%$ and all the data points fall within an absolute deviation of no more than $10 \%$. While, the MLR-based model predicts nearly $56.4 \%$ data points within an absolute deviation of less than $5 \%$ and a total of $84.6 \%$ data points within an absolute deviation of less than $10 \%$. Only $15.4 \%$ data points have an AD of more than $10 \%$. This shows that the SVR-based model is highly accurate and has good generalization ability.

Table 4. Percentage distribution of predicted data points of Cu (II) biosorption efficiency by MLR model and SVR-based model in terms of absolute deviation (AD) for training data.

\begin{tabular}{|c|c|c|c|c|}
\hline $\begin{array}{c}\text { Absolute deviation } \\
(\mathrm{AD})(\%)\end{array}$ & $\begin{array}{c}\text { \% of SVR model } \\
\text { predicted values }\end{array}$ & $\begin{array}{c}\text { Cumulative } \\
\text { score }\end{array}$ & $\begin{array}{c}\text { \% of MLR model } \\
\text { predicted values }\end{array}$ & $\begin{array}{c}\text { Cumulative } \\
\text { score }\end{array}$ \\
\hline $\mathrm{AD}<2$ & 76.6 & 76.6 & 27.2 & 27.2 \\
\hline $2<\mathrm{AD}<5$ & 15.8 & 92.4 & 37.9 & 65.1 \\
\hline $5<\mathrm{AD}<10$ & 5.1 & 97.5 & 21.1 & 86.2 \\
\hline $\mathrm{AD}>10$ & 2.5 & 100 & 13.8 & 100 \\
\hline Total & 100 & & 100 & \\
\hline
\end{tabular}

Table 5. Percentage distribution of predicted data points of Cu (II) biosorption efficiency by MLR model and SVR-based model in terms of absolute deviation (AD) for test data.

\begin{tabular}{|c|c|c|c|c|}
\hline $\begin{array}{c}\text { Absolute deviation } \\
(\mathrm{AD})(\%)\end{array}$ & $\begin{array}{c}\text { \% of SVR model } \\
\text { predicted values }\end{array}$ & $\begin{array}{c}\text { Cumulative } \\
\text { score }\end{array}$ & $\begin{array}{c}\text { \% of MLR model } \\
\text { predicted values }\end{array}$ & $\begin{array}{c}\text { Cumulative } \\
\text { score }\end{array}$ \\
\hline $\mathrm{AD}<2$ & 61.5 & 61.5 & 23.1 & 23.1 \\
\hline $2<\mathrm{AD}<5$ & 30.8 & 92.3 & 33.3 & 56.4 \\
\hline $5<\mathrm{AD}<10$ & 7.7 & 100 & 28.2 & 84.6 \\
\hline $\mathrm{AD}>10$ & 00.00 & & 15.4 & 100 \\
\hline Total & 100 & & 100 & \\
\hline
\end{tabular}




\section{CASE STUDY II}

\section{PREDICTION OF ARSENIC (III) BIOSORPTION EFFICIENCY}

In this study biosorption efficiency of As (III) ions has been predicted with the developed SVR-based model and the MLR model. Biosorption data for the present work have been taken from available published literature [64] where the input parameters are taken as: initial As (III) concentration, biosorbent dosage, contact time and temperature. The whole dataset of 81 samples are divided into a training dataset and a testing dataset using the simple random sampling (SRS) technique, in the size ratio of $80 \%$ (65 data points) and $20 \%$ (16 data points) respectively.

\section{Analysis of the MLR model}

From the literature [64] we found that biosorption of As (III) (y) depends on initial As (III) concentration $\left(m_{1}\right)$, biosorbent dosage $\left(m_{2}\right)$, contact time $\left(m_{3}\right)$ and temperature $\left(m_{4}\right)$ and the following MLR model equation has been obtained:

$$
\mathrm{y}=54.5550-0.3314\left(m_{1}\right)+1.3083\left(m_{2}\right)+0.2120\left(m_{3}\right)+0.2442\left(m_{4}\right)
$$

These independent variables are found to play a significant role into the regression.

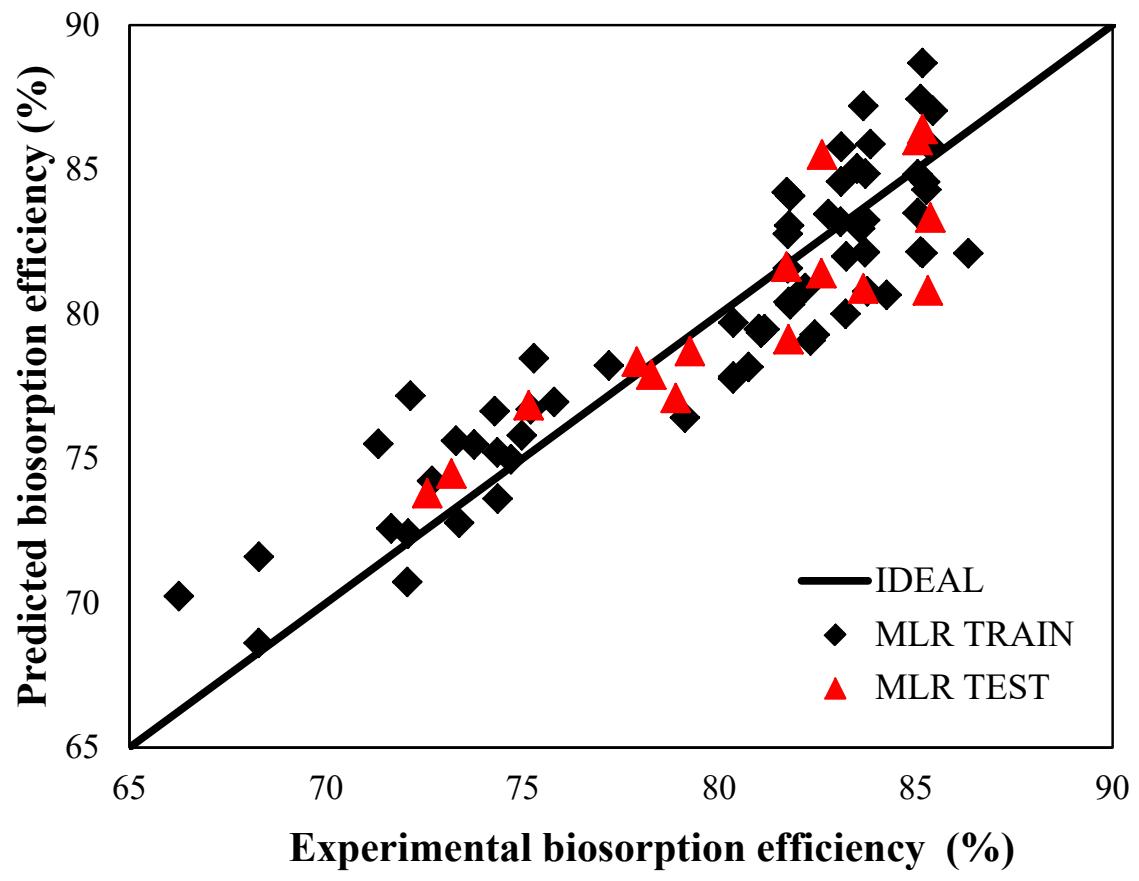

Figure 7: Performance of MLR model using a training data and a test data for predicting the biosorption efficiency of As(III). 
Performance assessment of the MLR model for the prediction of biosorption efficiency As (III) based on statistical parameters like AARE, R, RMSE, SD and MRE. A comparison between the predicted values of As(II) biosorption efficiency by the MLR model and those calculated from the experimental data using the training dataset and the test dataset is shown in the Fig. 7 and Table 6.

Table 6: Model evaluation parameters for MLR model using the training data and the test data

\begin{tabular}{|c|c|c|}
\hline MLR Model evaluation parameter & Train data & Test data \\
\hline AARE (\%) & 2.3206 & 1.74 \\
\hline R & 0.9066 & 0.8775 \\
\hline RMSE & 0.0275 & 0.0233 \\
\hline SD & 4.7056 & 4.1988 \\
\hline MRE & 0.0231 & 0.0177 \\
\hline Q $^{2}$ LOO (Train data),Q ${ }^{2} \operatorname{ext}($ Test data) & 0.8217 & 0.7533 \\
\hline
\end{tabular}

\section{Analysis of the SVR-based model}

Similar procedure as discussed in "Case Study I" were used to develop the SVR model by grid search methodology with a 10 -fold cross validation. The obtained optimal values of the model parameters are given in Table 7.

Table 7. Optimal parameters for SVR-based model for biosorption efficiency of As (III).

\begin{tabular}{|l|l|l|c|c|c|c|c|}
\hline $\begin{array}{l}\text { Property to } \\
\text { be predicted }\end{array}$ & $\mathrm{C}$ & $\begin{array}{l}\gamma= \\
1 / 2 \sigma^{2}\end{array}$ & $\varepsilon$ & $\begin{array}{c}\text { Kernel } \\
\text { type }\end{array}$ & $\begin{array}{c}\text { Type of } \\
\text { loss } \\
\text { function }\end{array}$ & $\begin{array}{c}\text { Number of } \\
\text { support } \\
\text { vectors }\end{array}$ & $\begin{array}{c}\text { Number of } \\
\text { training } \\
\text { points }\end{array}$ \\
\hline $\begin{array}{l}\text { Biosorption } \\
\text { efficiency(\%) }\end{array}$ & 32768 & 0.055 & 0.0848 & RBF & $\begin{array}{c}\varepsilon- \\
\text { insensitive }\end{array}$ & 46 & 65 \\
\hline
\end{tabular}

The training and test course has been constructed using the training data set and test data set as shown in the Fig. 8 and Fig. 9 respectively. One can observe that the predicted data points for the training as well as for testing set lies very close to the experimental data. Further, it can be clearly seen that the SVR prediction results are much improved over the test data set. 
Materials Research Foundations Vol. 5

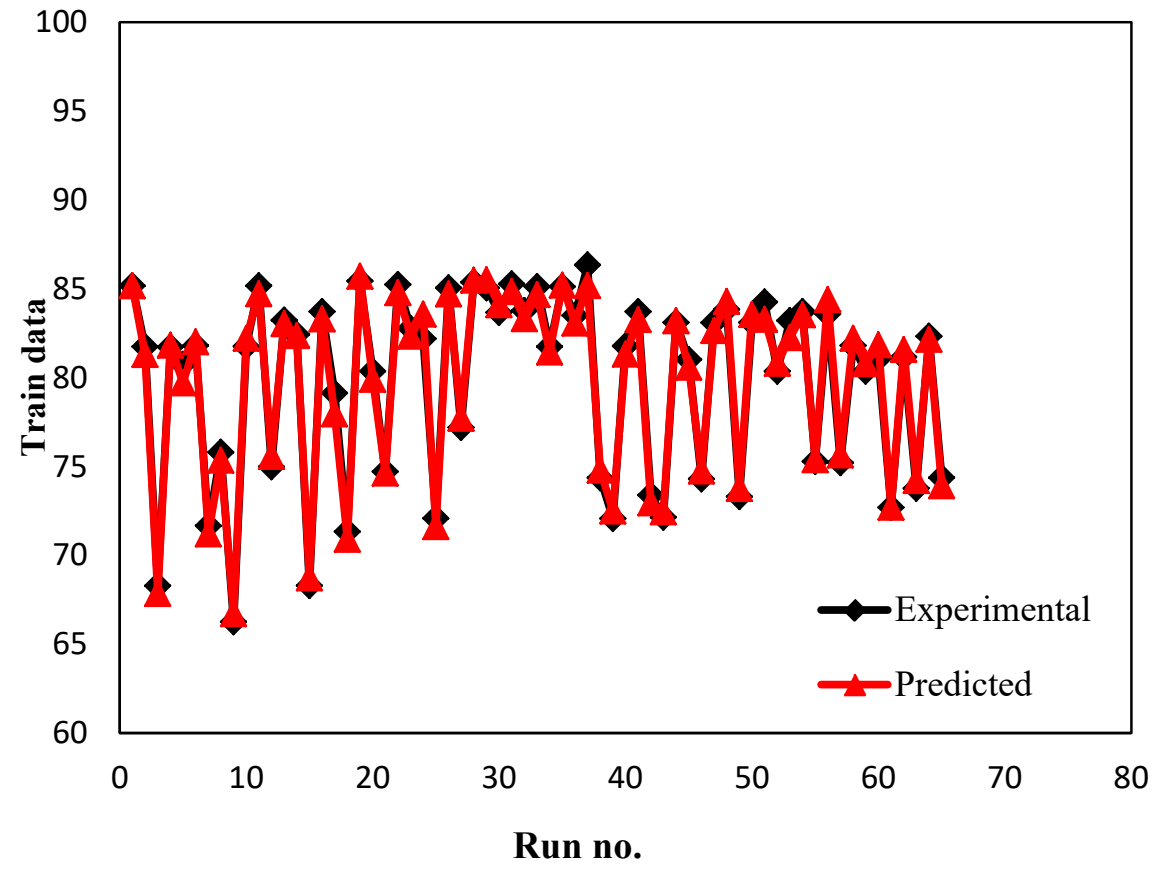

Figure 8. Training course curve for the Prediction of As(III) biosorption efficiency(\%)

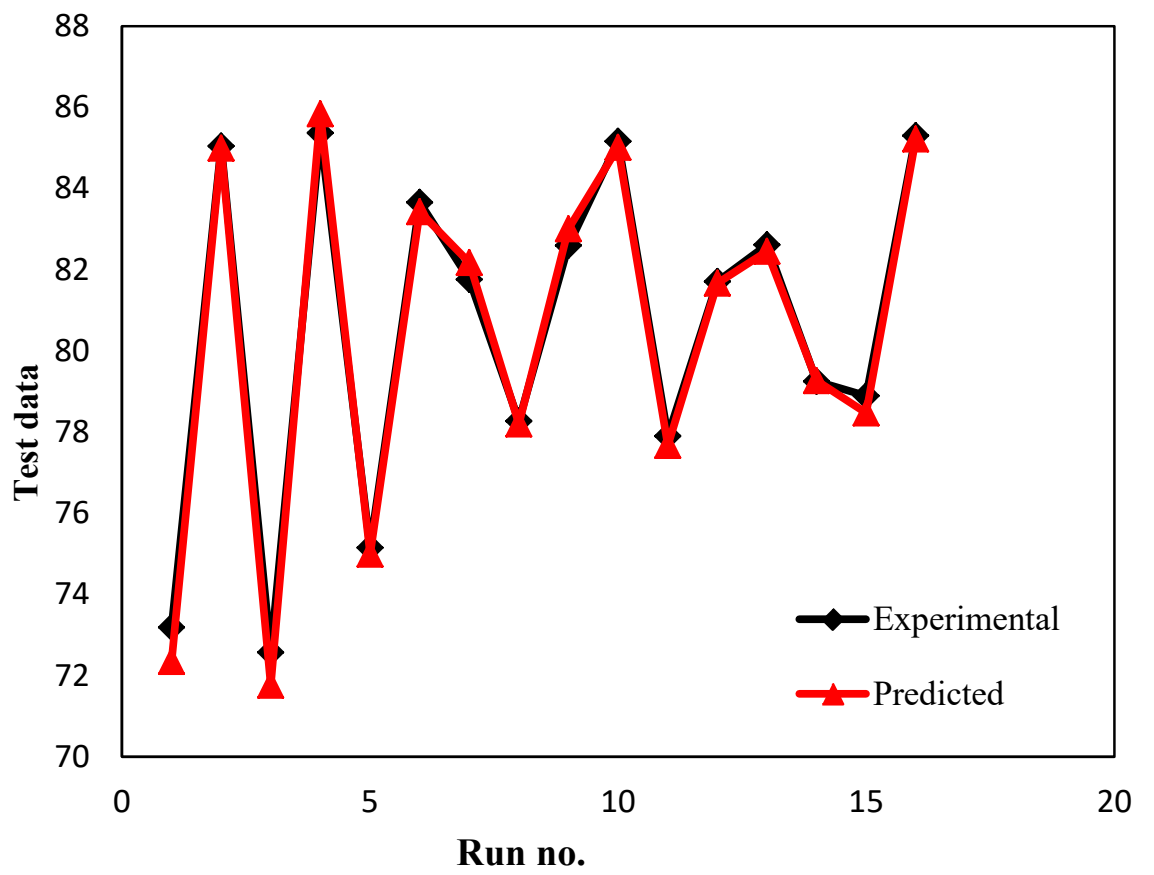

Figure 9. Test course curve for the Prediction of As(III) biosorption efficiency(\%) 


\section{Comparison of SVR-based model with the MLR model}

A comparison of the prediction performances of the developed MLR model with the SVR-based model is shown in Table 8 and Fig. 10.

Table 8. Model evaluation parameters for SVR-based model and MLR model using the test data.

\begin{tabular}{|c|c|c|}
\hline SVR Model evaluation parameter & SVR-based model & MLR model \\
\hline AARE $(\%)$ & 0.5591 & 1.74 \\
\hline R & 0.9905 & 0.8775 \\
\hline RMSE & $5.6418 \mathrm{E}-05$ & 0.0233 \\
\hline SD & 3.6245 & 4.1988 \\
\hline MRE & 0.00562 & 0.0177 \\
\hline
\end{tabular}

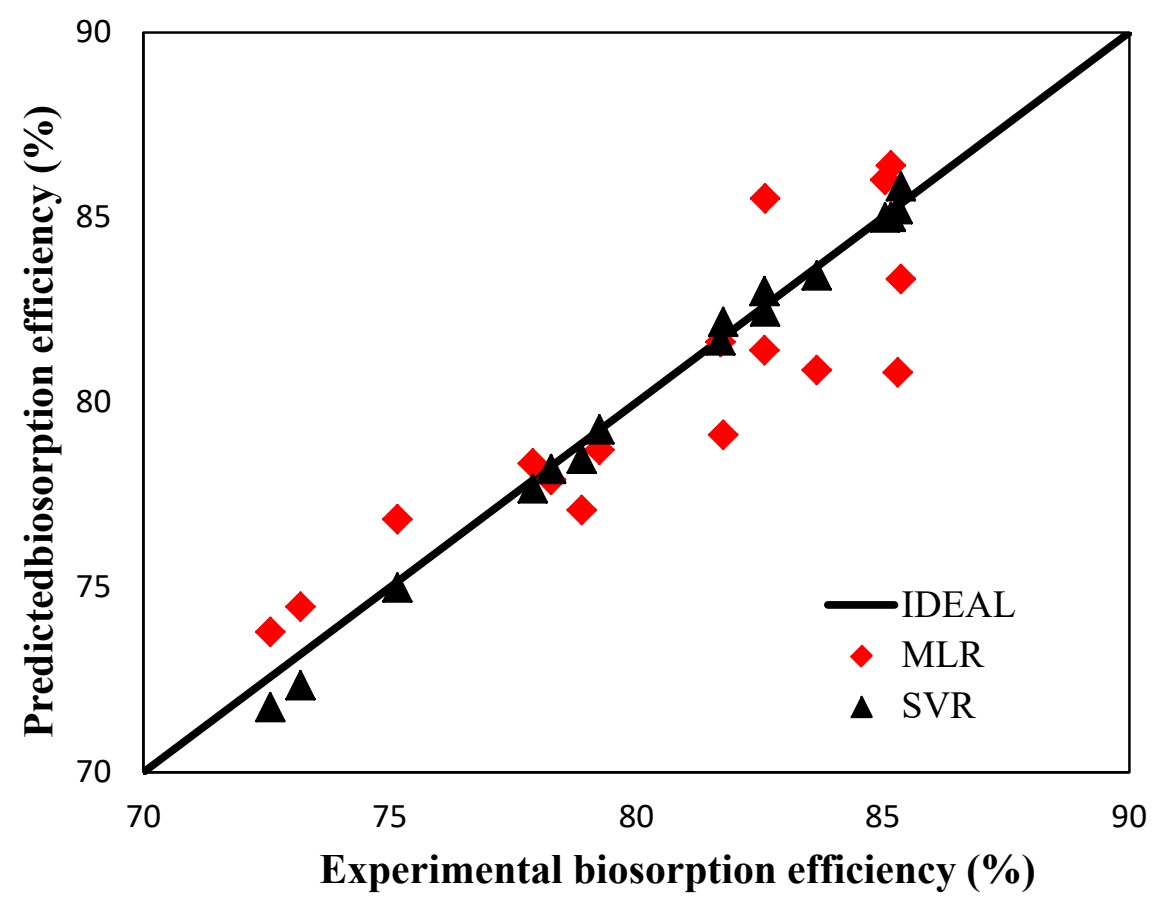

Figure 10. Comparison of SVR model with the MLR model using the test data set.

Table 9 illustrates the distribution of predicted data points of As (III) biosorption efficiency by the SVR-based model in terms of absolute deviation for the training data set. It has been found that the SVR-based model predicts nearly $90.7 \%$ data points within an absolute deviation of less than $1 \%$. Only $9.23 \%$ data points within an absolute deviation of less than $5 \%$ and no deviation have been found above an $\mathrm{AD}$ of more than $5 \%$. Whereas, it is observed that the MLR-based model predicts nearly $95.38 \%$ data 
points within an absolute deviation of less than $5 \%$ and a total of $4.6 \%$ data points have an $\mathrm{AD}$ of more than $5 \%$.

Table 10 depicts the distribution of predicted data points of As (III) biosorption efficiency by MLR and SVR-based model in terms of absolute deviation for the test data set. It is observed that the SVR based model predicts nearly $56.25 \%$ data points within an absolute deviation of less than $1 \%$ and all the data points fall within an absolute deviation of no more than 5\%. While, the MLR-based model predicts nearly $25 \%$ data points within an absolute deviation of less than $1 \%$ and a total of $93.75 \%$ data points within an absolute deviation of less than 5\%. Only $6.25 \%$ data points have an AD of more than $5 \%$.

Table 9. Percentage distribution of predicted data points of the sorption efficiency of As (III) by MLR model and SVR- based model in terms of absolute deviation (AD) for the training data set.

\begin{tabular}{|c|c|c|c|c|}
\hline $\begin{array}{c}\text { Absolute deviation } \\
(\mathrm{AD})(\%)\end{array}$ & $\begin{array}{c}\text { \% of MLR model } \\
\text { predicted values }\end{array}$ & $\begin{array}{c}\text { Cumulative } \\
\text { score }\end{array}$ & $\begin{array}{c}\text { \% of SVR model } \\
\text { predicted values }\end{array}$ & $\begin{array}{c}\text { Cumulative } \\
\text { score }\end{array}$ \\
\hline $\mathrm{AD}<1$ & 20 & 20 & 90.7692 & 90.7692 \\
\hline $1<\mathrm{AD}<5$ & 75.3846 & 95.3846 & 9.2308 & 100 \\
\hline $\mathrm{AD}>5$ & 4.6154 & 100 & 0.00 & \\
\hline Total & 100 & & 100 & \\
\hline
\end{tabular}

Table 10. Percentage distribution of predicted data points of the sorption efficiency of As (III) by MLR model and SVR- based model in terms of absolute deviation (AD) for test data.

\begin{tabular}{|c|c|c|c|c|}
\hline $\begin{array}{c}\text { Absolute deviation } \\
(\mathrm{AD})(\%)\end{array}$ & $\begin{array}{c}\% \text { of MLR model } \\
\text { predicted values }\end{array}$ & $\begin{array}{c}\text { Cumulative } \\
\text { score }\end{array}$ & $\begin{array}{c}\% \text { of SVR model } \\
\text { predicted values }\end{array}$ & $\begin{array}{c}\text { Cumulative } \\
\text { score }\end{array}$ \\
\hline $\mathrm{AD}<1$ & 25 & 25 & 56.25 & 56.25 \\
\hline $1<\mathrm{AD}<5$ & 68.75 & 93.75 & 43.75 & 100 \\
\hline $\mathrm{AD}>5$ & 6.25 & 100 & 0.00 & \\
\hline Total & 100 & & 100 & \\
\hline
\end{tabular}




\section{CASE STUDY - III}

\section{PREDICTION OF THE SORPTION CAPACITY OF LEAD (II)}

To predict the sorption capacity of Lead (II) using an agricultural by-product 'tree fern', as a low cost biosorbent, similar procedure has been adopted as discussed in earlier case studies. Biosorption data for SVR, MLR and ANN model have been taken from the available published literature $[65,66]$. The entire dataset consisting of 145 samples are divided into training dataset and testing dataset using the simple random sampling (SRS) technique, in the size ratio of $80 \%$ (116 data points) and $20 \%$ (29 data points) respectively. Finally developed SVR model has been evaluated and validated on the basis of statistical parameters as well as by comparing it with the commonly used multiple linear regression (MLR) model and ANN model.

Analysis of the MLR model

The MLR model was developed for predicting the sorption capacity of lead (II) ions (y) with the independent input parameters being: initial lead ion concentration $\left(\mathrm{x}_{1}\right)$, temperature $\left(\mathrm{x}_{2}\right), \mathrm{pH}\left(\mathrm{x}_{3}\right)$ and contact time $\left(\mathrm{x}_{4}\right)$.

The following MLR model equation has been obtained through MS-Excel (2007):

$\mathrm{y}=-141.8444+0.0398\left(\mathrm{x}_{1}\right)+0.4826\left(\mathrm{x}_{2}\right)+2.8756\left(\mathrm{x}_{3}\right)+0.1336\left(\mathrm{x}_{4}\right)$

The independent variables are found to be significant into the regression.

In this study, performance of the developed MLR model for the training and test data set is shown in the Fig. 11 as well as also, given in the Table 11. It can be seen from Table 11 that the performance of the MLR model for test data set (unseen data) is poor as compared to the training data set.

Table 11. Model evaluation parameters for MLR model using the training data and the test data.

\begin{tabular}{|c|c|c|}
\hline MLR Model evaluation parameter & Train data & Test data \\
\hline AARE (\%) & 21.1178 & 25.0056 \\
\hline R & 0.78661 & 0.7613 \\
\hline RMSE & 0.0469 & 0.1188 \\
\hline SD & 8.3075 & 8.3246 \\
\hline MRE & 0.1745 & 0.1799 \\
\hline $\mathrm{Q}^{2}$ LOO (Train data), ${ }^{2} \operatorname{ext}($ Test data) & 0.6153 & 0.5764 \\
\hline
\end{tabular}




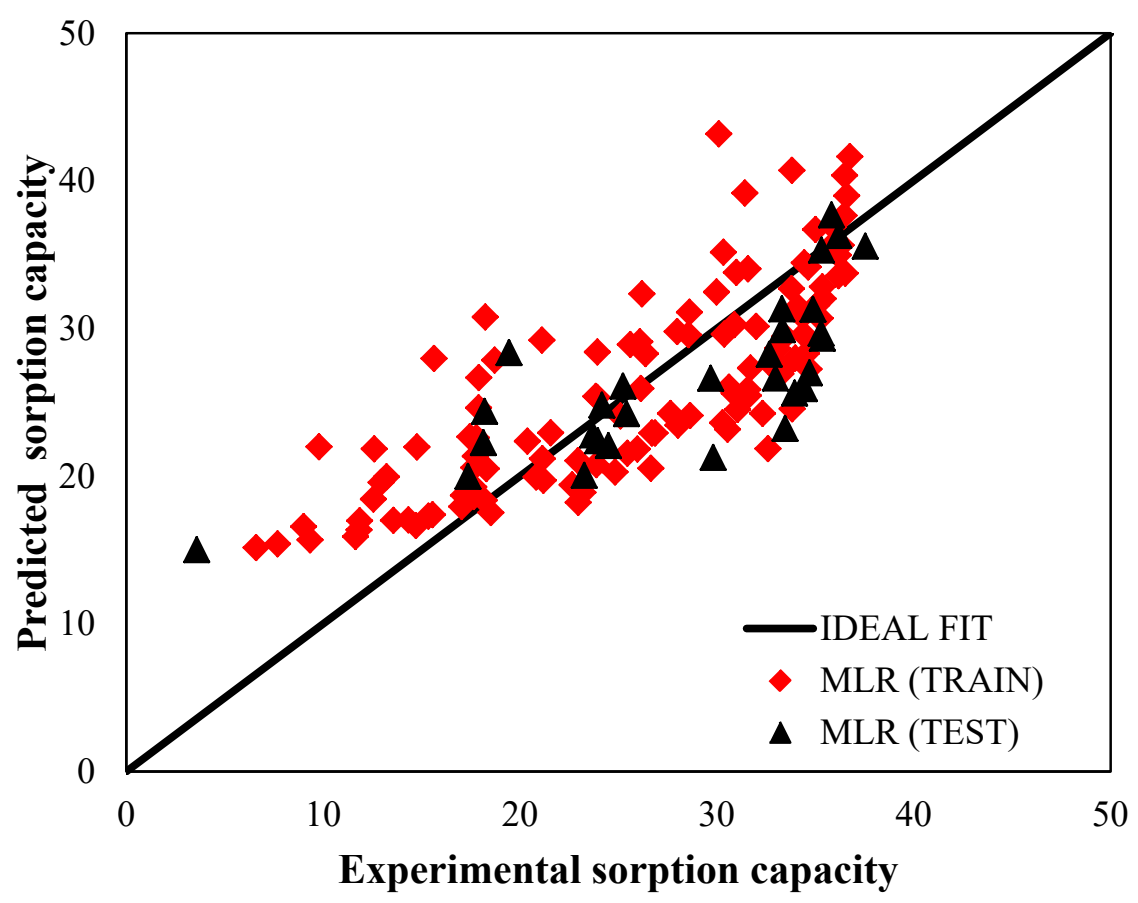

Figure 11. Performance of MLR model using training data and test data for predicting the sorption capacity of lead(II).

\section{Analysis of ANN model}

The schematic representation of neural networks architecture shown in Fig. 12. comprises of: (1) input layer (independent variables), (2) hidden layers, (3) and the output layer (dependent variables). Three layered multiple feed forward neural networks (4:12:1) have been used for modeling of the sorption capacity of lead (II) with 4 - neuron for initial lead ion concentration $(\mathrm{mg} / \mathrm{L})$, temperature $\left({ }^{\circ} \mathrm{C}\right), \mathrm{pH}$ of the solution and contact time (min) at the input layer, 12 - neuron at hidden layer and 1- neuron for the sorption capacity at the output layer. The entire data set of 145 samples is partitioned into three subsets consisting training dataset, $65 \%$ (data), validation dataset, $15 \%$ (data) and test dataset, $20 \%$ (data). The numbers of input and output neurons are set according to the nature of the problem whereas an appropriate number of neuron in the hidden layer has been chosen by trial and error method as insufficient neurons may cause under fitting while too many neurons might lead to over fitting [67, 68, 69]. The training of the ANN model is carried out with the complete input data set to the network till the MSE is minimized [70, 71, 72, 73]. A model should be trained properly in order to have its high correlation coefficient (R) close to 1 and low MSE. The ANN toolbox present in MATLAB has been used in this study to develop the model. 


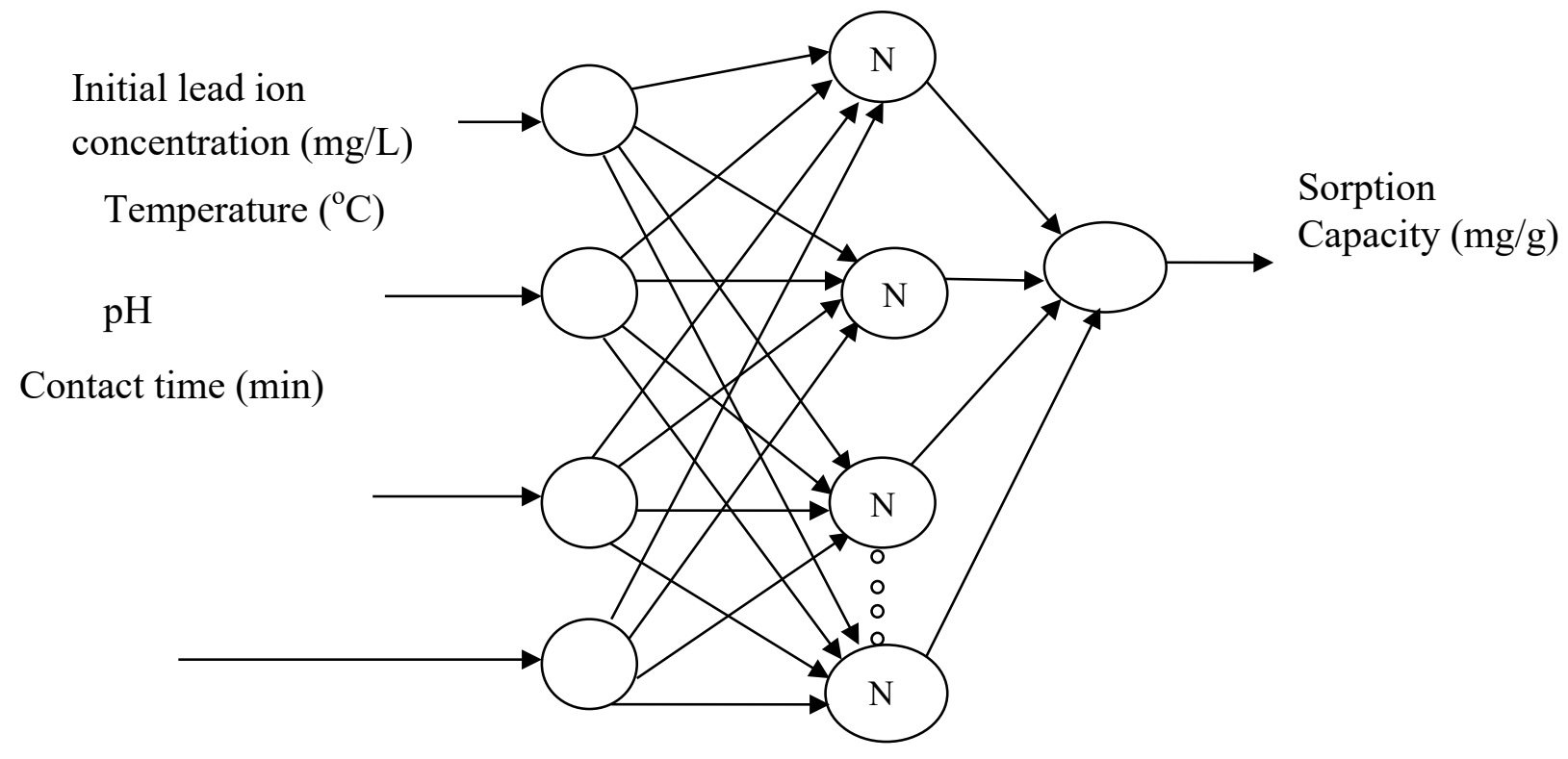

Figure 12. Schematic representation of ANN architecture.

Fig. 13 demonstrates that both the predicted values for the training data as well as the test data lie close to the ideal fit line. Table 12 exhibits the model evaluation parameters of the ANN model for both the training data as well as the test data.

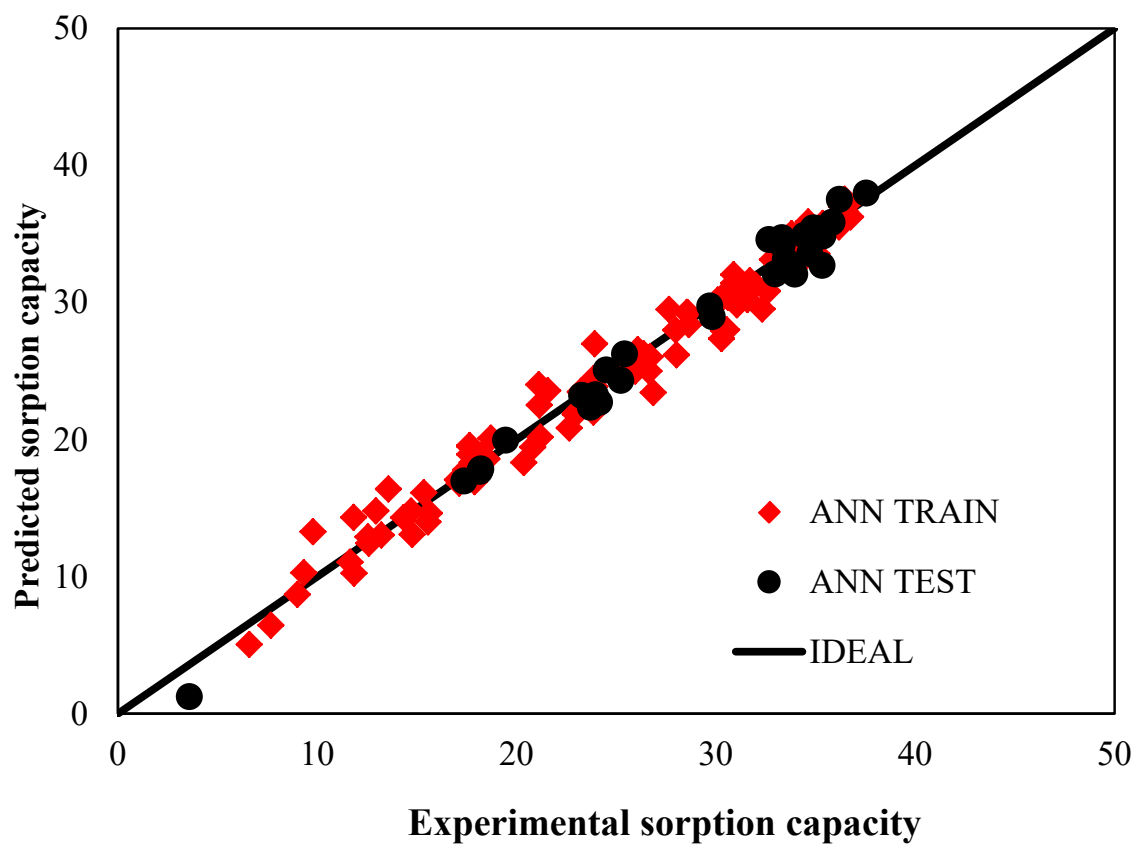

Figure 13. Performance of ANN model using training data and test data for predicting the sorption capacity of lead(II). 
Table 12. Model evaluation parameters for ANN model using training and the test data.

\begin{tabular}{|c|c|c|}
\hline Model evaluation parameter & Train data & Test data \\
\hline AARE $(\%)$ & 4.4545 & 4.941 \\
\hline $\mathrm{R}$ & 0.9889 & 0.9845 \\
\hline RMSE & 0.0048 & 0.0587 \\
\hline SD & 8.2293 & 7.9204 \\
\hline MRE & 0.0444 & 0.0912 \\
\hline $\mathrm{Q}^{2} \mathrm{LOO}$ (Train data), ${ }^{2}$ ext(Test data) & 0.9826 & 0.9779 \\
\hline
\end{tabular}

\section{Analysis of the SVR-based model}

An SVR model with the same data set of 145 samples is developed using the procedure described in the previous case studies, the obtained optimal values of the SVR model parameter is given below in Table 13 .

Table 13. Optimal parameters for SVR-based model for sorption capacity of Lead (II).

\begin{tabular}{|c|c|c|c|c|c|c|c|}
\hline $\begin{array}{c}\text { Property } \\
\text { to be } \\
\text { predicted }\end{array}$ & $\mathrm{C}$ & $\begin{array}{c}\gamma= \\
1 / 2 \sigma^{2}\end{array}$ & $\varepsilon$ & $\begin{array}{c}\text { Kernel } \\
\text { type }\end{array}$ & $\begin{array}{c}\text { Type } \\
\text { of loss } \\
\text { function }\end{array}$ & $\begin{array}{c}\text { Number } \\
\text { of support } \\
\text { vectors }\end{array}$ & $\begin{array}{c}\text { Number of } \\
\text { training } \\
\text { points }\end{array}$ \\
\hline $\begin{array}{c}\text { Sorption } \\
\text { capacity } \\
{[\mathrm{mg} / \mathrm{g}]}\end{array}$ & 32768 & 0.058 & 0.09 & RBF & $\begin{array}{c}\varepsilon^{-} \\
\text {insensitive }\end{array}$ & 70 & 116 \\
\hline
\end{tabular}

After optimizing the SVR parameters, training course curve and test course has been constructed as shown in Fig. 14 and Fig. 15 respectively. 
New Polymeric Composite Materials

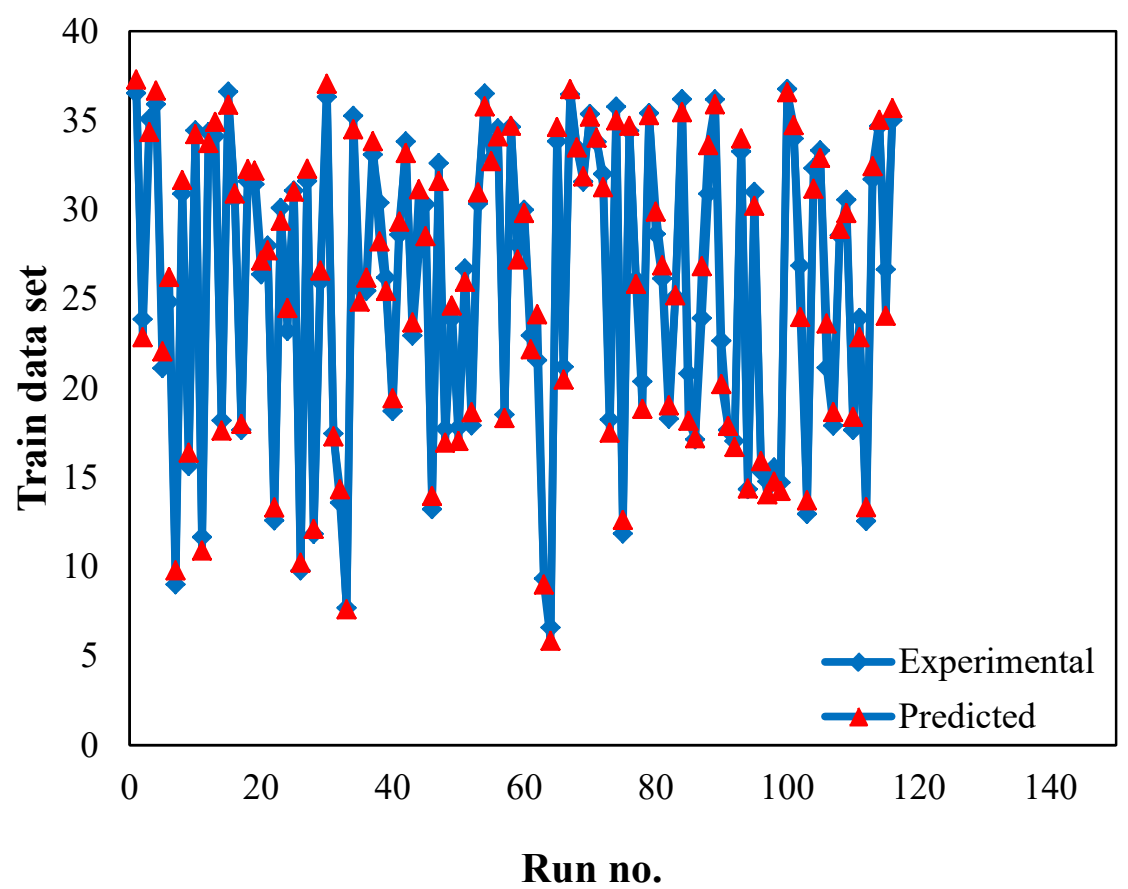

Figure 14. Training course curve for predicting the sorption capacity of lead (II) using SVR.

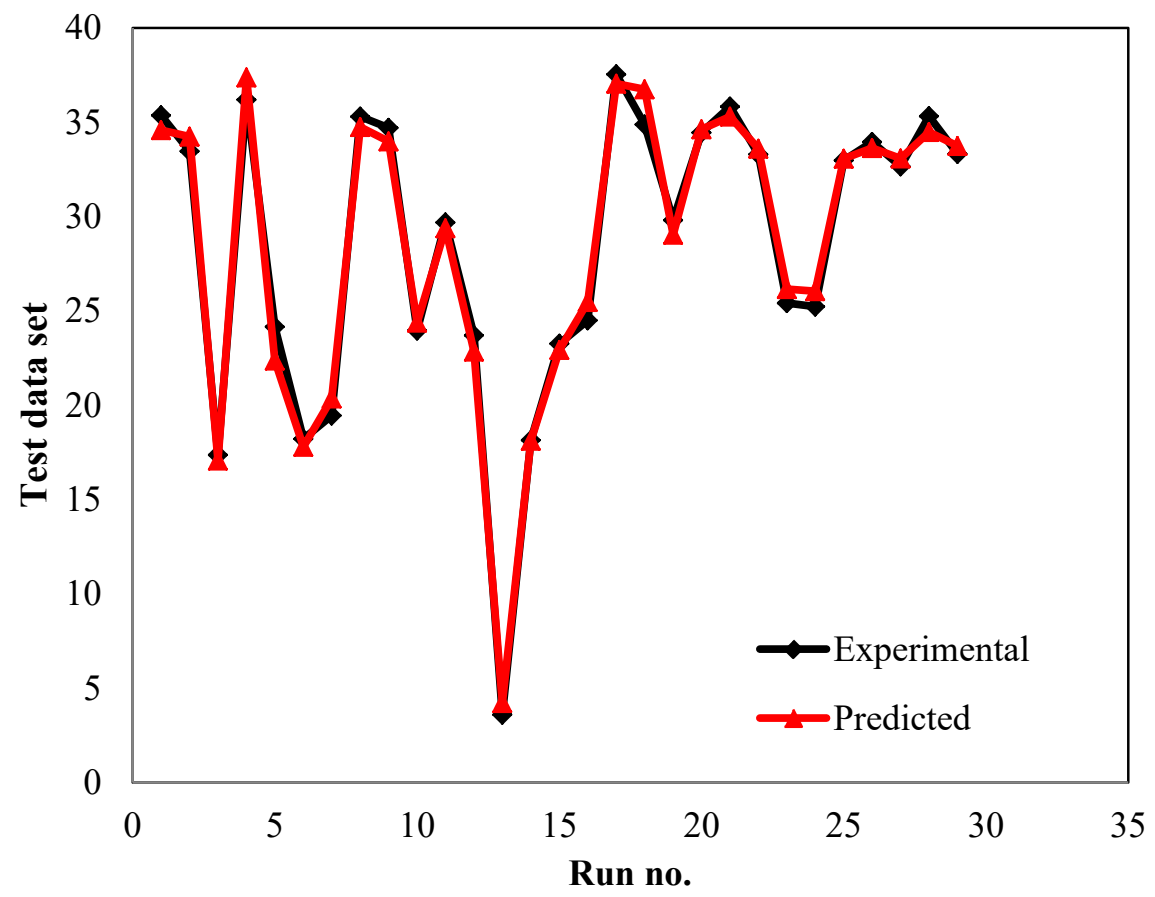

Figure 15. Test course curve for predicting the sorption capacity of lead (II) using SVR.

A comparison between the predicted values of the sorption capacity of lead (II) by the SVR-based model and those calculated from the experimental data using the training 
dataset and the test dataset has been shown in the Fig. 16 and the model evaluation parameters are given in the Table 14.

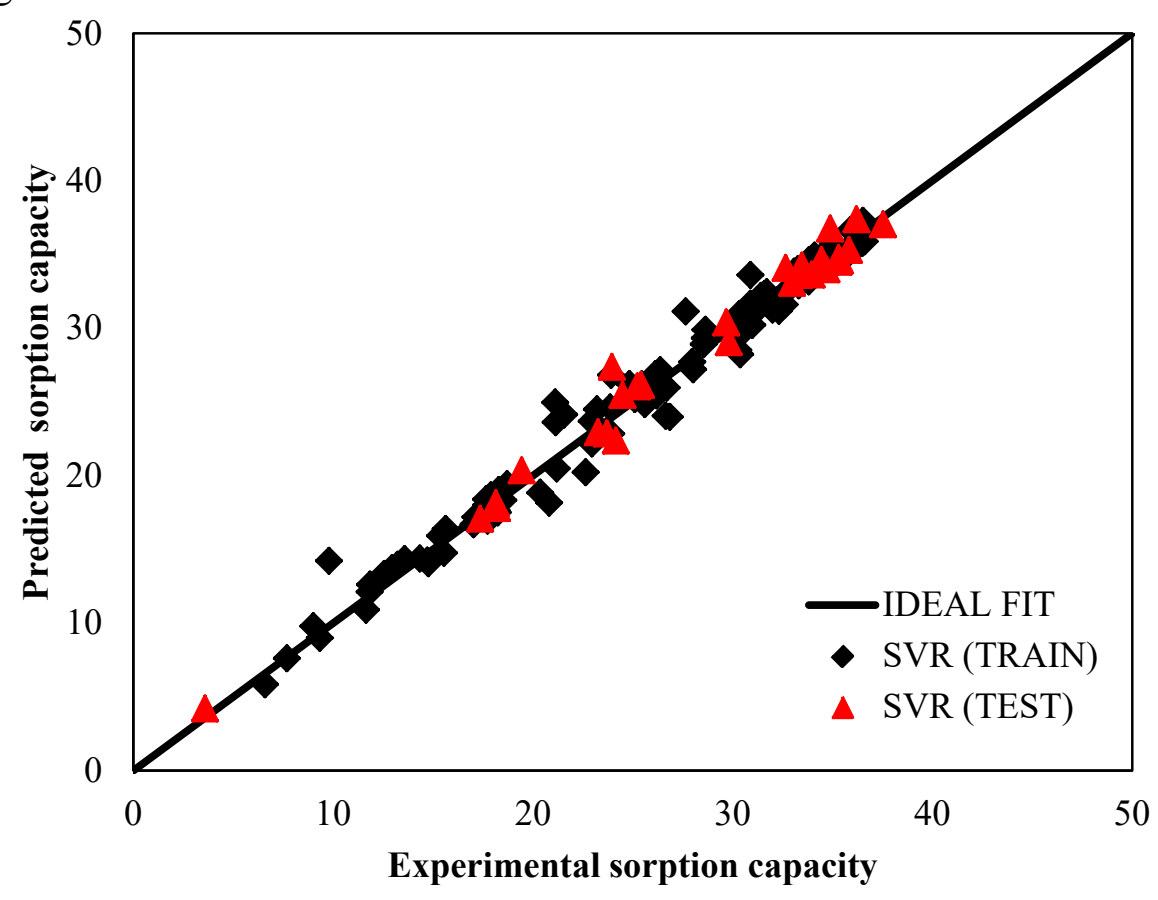

Figure 16. SVR simulation of sorption capacity ( $\mathrm{mg} / \mathrm{g}$ ) of lead (II) ions with optimal parameters using training data and test data set.

Table 14. Model evaluation parameters for SVR-based model using training and the test data.

\begin{tabular}{|c|r|c|}
\hline SVR Model evaluation parameter & \multicolumn{1}{|c|}{ Train data } & Test data \\
\hline AARE (\%) & 3.9874 & 3.3816 \\
\hline R & 0.9901 & 0.9914 \\
\hline RMSE & 0.0041 & 0.0025 \\
\hline SD & 8.2529 & 7.8962 \\
\hline MRE & 0.0399 & 0.0338 \\
\hline$Q^{2}$ LOO(Train data), ${ }^{2}$ ext(Test data) & 0.9800 & 0.9845 \\
\hline
\end{tabular}

Comparison of SVR-based model with ANN and MLR model

Prediction performance of the developed SVR-based model has been compared with the ANN and the MLR model as shown in Fig. 17. Table 15 clearly depicts the superior prediction performance of the SVR-based model. 


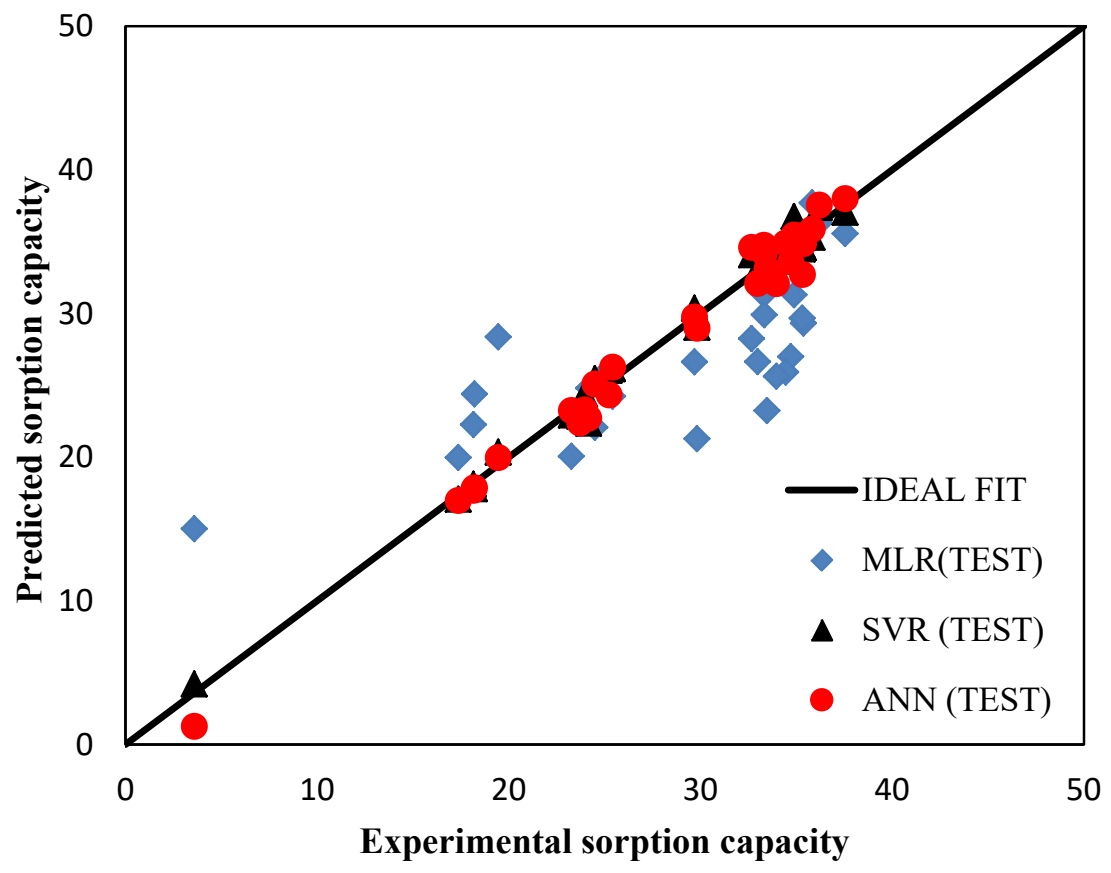

Figure 17. Comparison of SVR model with MLR and ANN model for predicting the sorption capacity ( $\mathrm{mg} / \mathrm{g}$ ) of lead (II) ions using the test data set.

Table 15. Model evaluation parameters for SVR-based model, ANN and MLR model using test data set.

\begin{tabular}{|c|c|c|c|}
\hline Model evaluation parameter & SVR-based model & ANN model & MLR model \\
\hline AARE (\%) & 3.38 & 4.941 & 25.01 \\
\hline R & 0.9915 & 0.9845 & 0.7613 \\
\hline RMSE & 0.0025 & 0.0587 & 0.1188 \\
\hline SD & 7.8962 & 7.9204 & 8.3246 \\
\hline MRE & 0.0338 & 0.0912 & 0.1799 \\
\hline
\end{tabular}

Table 16 illustrates the distribution of predicted data points of lead (II) sorption capacity by SVR-based model in terms of absolute deviation for the training data set. It has been found that the SVR-based model predicts nearly $77.58 \%$ data points within an absolute deviation of less than $5 \%$ and a total of $91.37 \%$ data points within an absolute deviation of less than $10 \%$. Only $0.86 \%$ data points have an $\mathrm{AD}$ of more than $20 \%$. Whereas, it is observed that the ANN model have 69.83 percent data points within an absolute deviation of less than $5 \%$ and a total of 86.21 per cent data points within an absolute deviation of less than $10 \%$. Only $96.55 \%$ data points have an AD of more than $20 \%$. 
MLR-based model predicts nearly $14.65 \%$ data points within an absolute deviation of less than $5 \%$ and a total of $36.2 \%$ data points within an absolute deviation of less than $10 \%$. Only $31.03 \%$ data points have an AD of more than $20 \%$.

Table 17 depicts the distribution of predicted data points of lead (II) sorption capacity by MLR and SVR-based model in terms of absolute deviation for the test data set. It is observed that the SVR based model predicts nearly $86.2 \%$ data points within an absolute deviation of less than $5 \%$ and a total of $93.10 \%$ data points within an absolute deviation of less than $10 \%$ and all the data points fall within an absolute deviation of not more than $20 \%$. While, it is found that ANN model have 79.31 percent data points within an absolute deviation of less than $5 \%$ and a total of $96.55 \%$ data points within an absolute deviation of less than $10 \%$. Only $3.44 \%$ data points have an $\mathrm{AD}$ of more than $20 \%$.

MLR-based model predicts nearly $20.68 \%$ data points within an absolute deviation of less than $5 \%$ and a total of $37.93 \%$ data points within an absolute deviation of less than $10 \%$. Only $31.03 \%$ data points have an AD of more than $20 \%$. This shows that the SVRbased model is highly accurate and has good generalization ability for the unseen test data set.

Table 16 Percentage distribution of predicted data points of the sorption capacity of lead (II) by MLR model and SVR- based model in terms of absolute deviation (AD) for training data.

\begin{tabular}{|c|c|c|c|c|c|c|}
\hline $\begin{array}{c}\text { Absolute } \\
\text { Deviation } \\
\mathrm{AD}(\%)\end{array}$ & $\begin{array}{c}\text { \% of MLR } \\
\text { model } \\
\text { predicted } \\
\text { values }\end{array}$ & $\begin{array}{c}\text { Cumulative } \\
\text { score }\end{array}$ & $\begin{array}{c}\text { \% of ANN } \\
\text { model } \\
\text { predicted } \\
\text { values }\end{array}$ & $\begin{array}{c}\text { Cumulative } \\
\text { score }\end{array}$ & $\begin{array}{c}\text { \% of SVR } \\
\text { model } \\
\text { predicted } \\
\text { values }\end{array}$ & $\begin{array}{c}\text { Cumulative } \\
\text { score }\end{array}$ \\
\hline $\mathrm{AD}<5$ & 14.6552 & 14.6552 & 69.8276 & 69.8276 & 77.5862 & 77.5862 \\
\hline $5<\mathrm{AD}<10$ & 21.5517 & 36.2069 & 16.3793 & 86.2069 & 13.7931 & 91.3793 \\
\hline $10<\mathrm{AD}<20$ & 32.7586 & 68.9655 & 10.3448 & 96.5517 & 7.7586 & 99.1379 \\
\hline $\mathrm{AD}>20$ & 31.0345 & 100 & 3.4483 & 100 & 0.8621 & 100 \\
\hline Total & 100 & & 100 & & 100 & \\
\hline
\end{tabular}


Table 17 Percentage distribution of predicted data points of the sorption capacity of lead(II) by MLR model, ANN and SVR-based model in terms of absolute deviation (AD) for test data set.

\begin{tabular}{|c|c|c|c|c|c|c|}
\hline $\begin{array}{c}\text { Absolute } \\
\text { Deviation } \\
\mathrm{AD}(\%)\end{array}$ & $\begin{array}{c}\text { \% of MLR } \\
\text { model } \\
\text { predicted } \\
\text { values }\end{array}$ & $\begin{array}{c}\text { Cumulative } \\
\text { score }\end{array}$ & $\begin{array}{c}\text { \% of ANN } \\
\text { model } \\
\text { predicted } \\
\text { values }\end{array}$ & $\begin{array}{c}\text { Cumulative } \\
\text { score }\end{array}$ & $\begin{array}{c}\text { \% of SVR } \\
\text { model } \\
\text { predicted } \\
\text { values }\end{array}$ & $\begin{array}{l}\text { Cumulative } \\
\text { score }\end{array}$ \\
\hline $\mathrm{AD}<5$ & 20.6897 & 20.6897 & 79.3103 & 79.3103 & 86.2069 & 86.2069 \\
\hline $5<\mathrm{AD}<10$ & 17.2414 & 37.9310 & 17.2414 & 96.5517 & 6.8965 & 93.1035 \\
\hline $10<\mathrm{AD}<20$ & 31.0345 & 68.9655 & 0.00 & 96.5517 & 6.8965 & 100 \\
\hline $\mathrm{AD}>20$ & 31.0345 & 100 & 3.4483 & 100 & 0.00 & \\
\hline Total & 100 & & 100 & & 100 & \\
\hline
\end{tabular}

\section{Performance Assessment of the Commonly Used MLR Model, ANN And SVR- Based Model in the Light of Existing Theory and Experimental Findings}

\section{A. Effect of initial conc. of lead (II)}

Experiments were performed at constant condition $\left(\mathrm{pH} 4.9\right.$, temperature $=20^{\circ} \mathrm{C}$, agitating speed $=300 \mathrm{rpm}$ ) to show the effect of various initial concentration of lead (II) on the sorption capacity of lead (II). It was observed that the sorption capacity of lead (II) initially increases due to ion exchange with the surface of cations on the tree fern and afterwards, it slows down representing a gradual uptake of cation exchange at the inner surface. The equilibrium sorption capacity increases from 18.2 to $41.5 \mathrm{mg} / \mathrm{g}$, as initial lead (II) concentration vary from 74.1 to $350 \mathrm{mg} / \mathrm{l}$.

Prediction of sorption capacity of lead (II) by SVR-based model, ANN and MLR model is shown in the Fig. 18 and it is found that the SVR-based model shows fair agreement with the experimental results and thus, it can be said that SVR-based has the best prediction ability and generalizability than ANN and MLR model. 
Materials Research Foundations Vol. 5
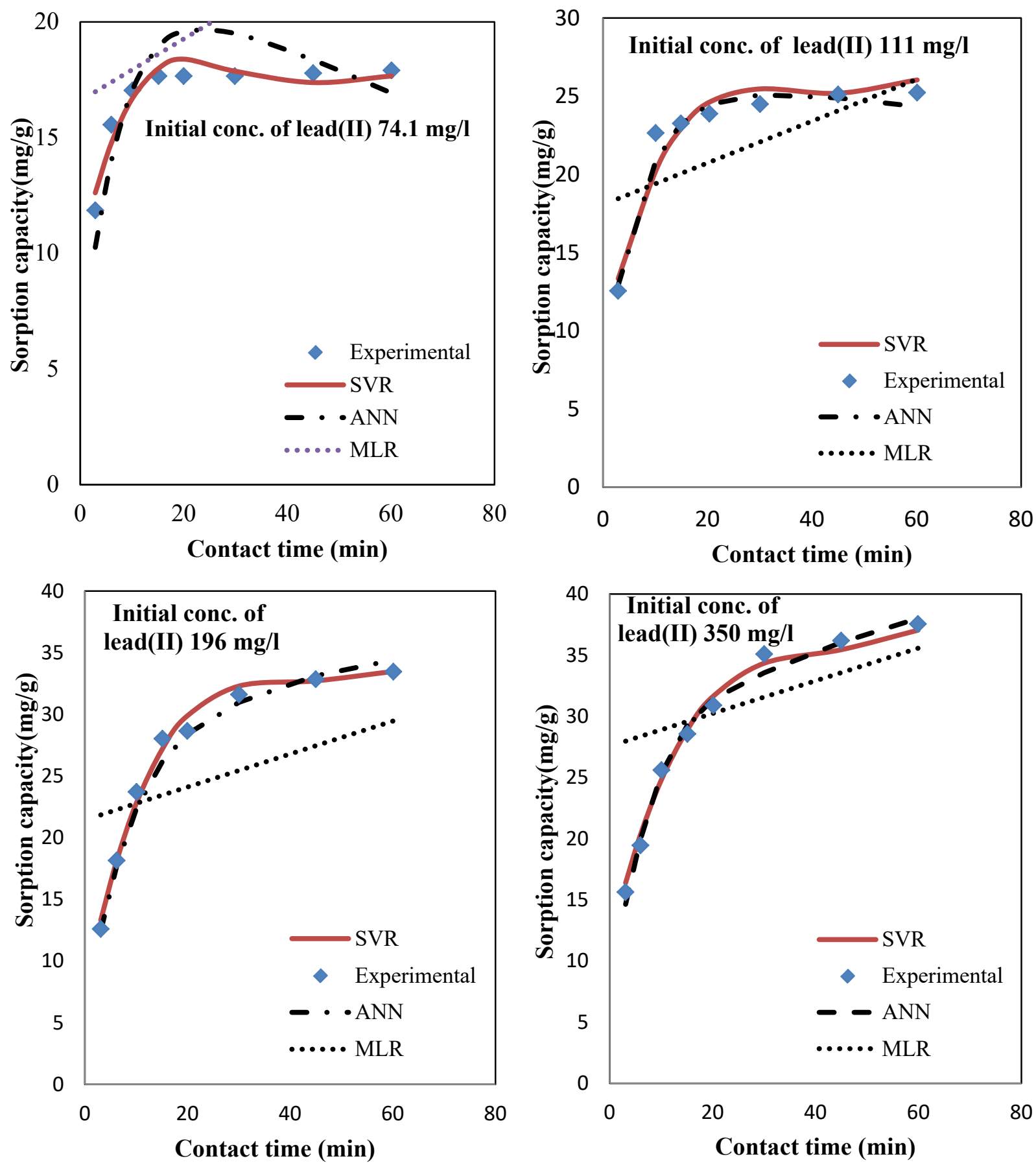

Figure 18 (a)-(e). Effect of initial lead (II) ion concentrations on the sorption capacity $(\mathrm{mg} / \mathrm{g})$ of lead against contact time ( $\mathrm{pH} 4.9$, temperature $=20^{\circ} \mathrm{C}$, agitating speed $=300$ rpm). 


\section{B. Effect of temperature on sorption capacity of lead (II)}

The effect of various temperatures on sorption capacity of lead (II) shown in Fig. 19 has been obtained by experiments performed with a constant condition ( $\mathrm{pH} 4.9$ initial lead concentration $200 \mathrm{mg} / \mathrm{L}$, agitating speed $=300 \mathrm{rpm}$ ). Sorption capacity increases with an increase in solution temperature from $278 \mathrm{~K}$ to $318 \mathrm{~K}$. However, the equilibrium sorption capacity was hardly affected by increased temperature. The values of rate constant were found to increase from $9.18 * 10^{-4}$ to $0.103 \mathrm{~g} / \mathrm{mg}$.min with an increase in the solution temperature from $278 \mathrm{~K}$ to $318 \mathrm{~K}$.

The variation in temperature influenced the time required to reach saturation with excellent agreement between the experimental and the predicted curves. It is observed that the SVR-based follows the same trends of the experimental results and is the better predictive model than the other two.
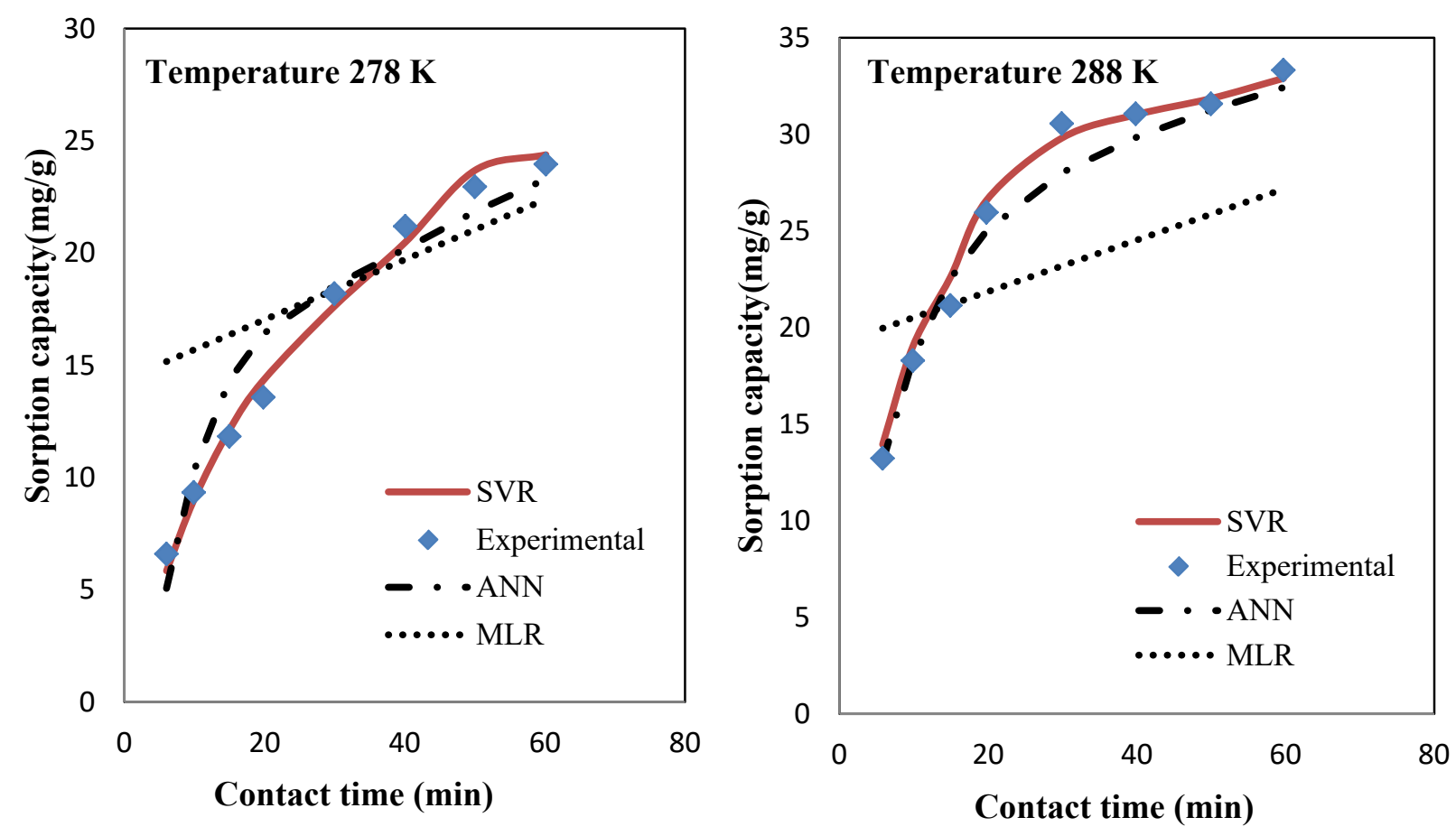
Materials Research Foundations Vol. 5
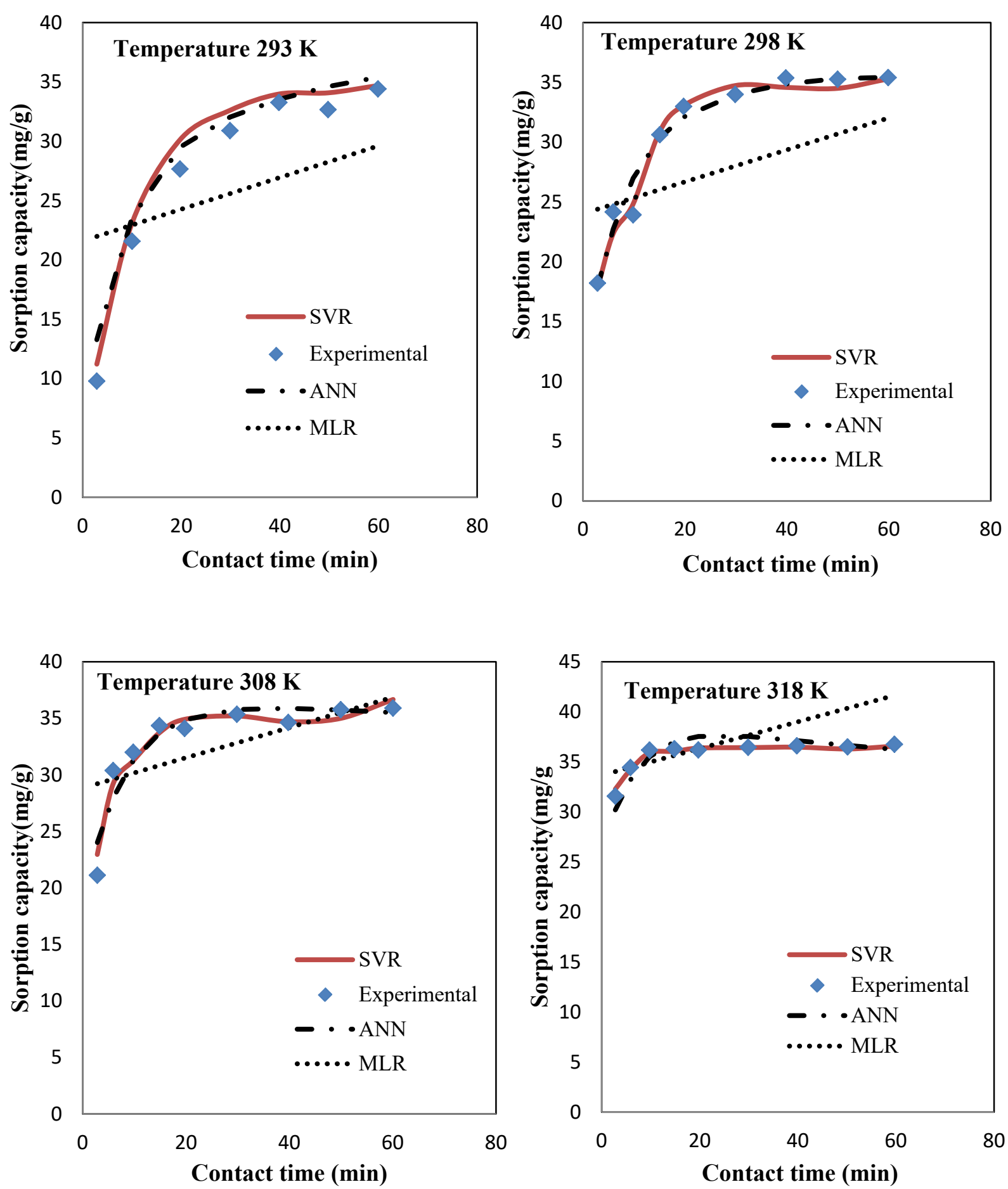

Figure 19 (a)-(e). Effect temperatures on the sorption capacity (mg/g) of lead against contact time ( $\mathrm{pH} 4.9$ initial lead concentration $200 \mathrm{mg} / \mathrm{L}$, agitating speed $=300 \mathrm{rpm}$ ). 


\section{Effect of pH on sorption capacity of lead (II)}

Ho [66] had performed the experiments at constant condition (initial lead concentration $200 \mathrm{mg} / \mathrm{L}$, temperature $=20^{\circ} \mathrm{C}$, agitating speed $=300 \mathrm{rpm}$ ) to show the effect of $\mathrm{pH}$ on sorption capacity of lead (II). The obtained results shown in Fig. 20 demonstrate that the sorption was initially fast and then slowed until equilibrium was reached, it is believed that ion exchange may have occurred in the beginning state of sorption. It was also found that at low $\mathrm{pH}$, surface of the tree fern becomes positively charged and as $\mathrm{pH}$ increased more ligands (neutral molecule) of tree fern gets attracted to the positively charged lead ion.

Predicting the effect of $\mathrm{pH}$ on sorption capacity of lead (II) by the SVR-based model, ANN and MLR and the data showed good compliance with the SVR model.
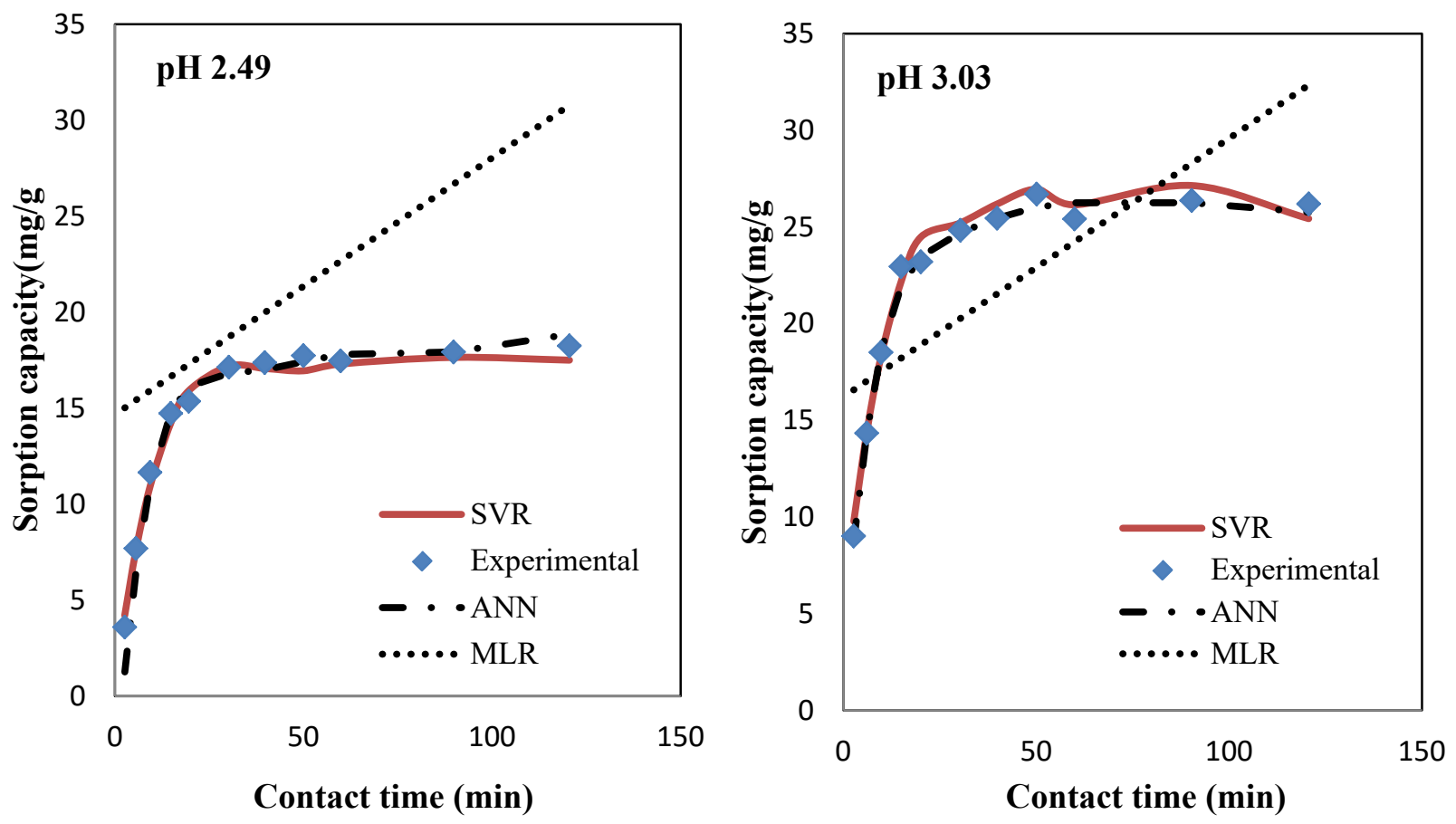
Materials Research Foundations Vol. 5
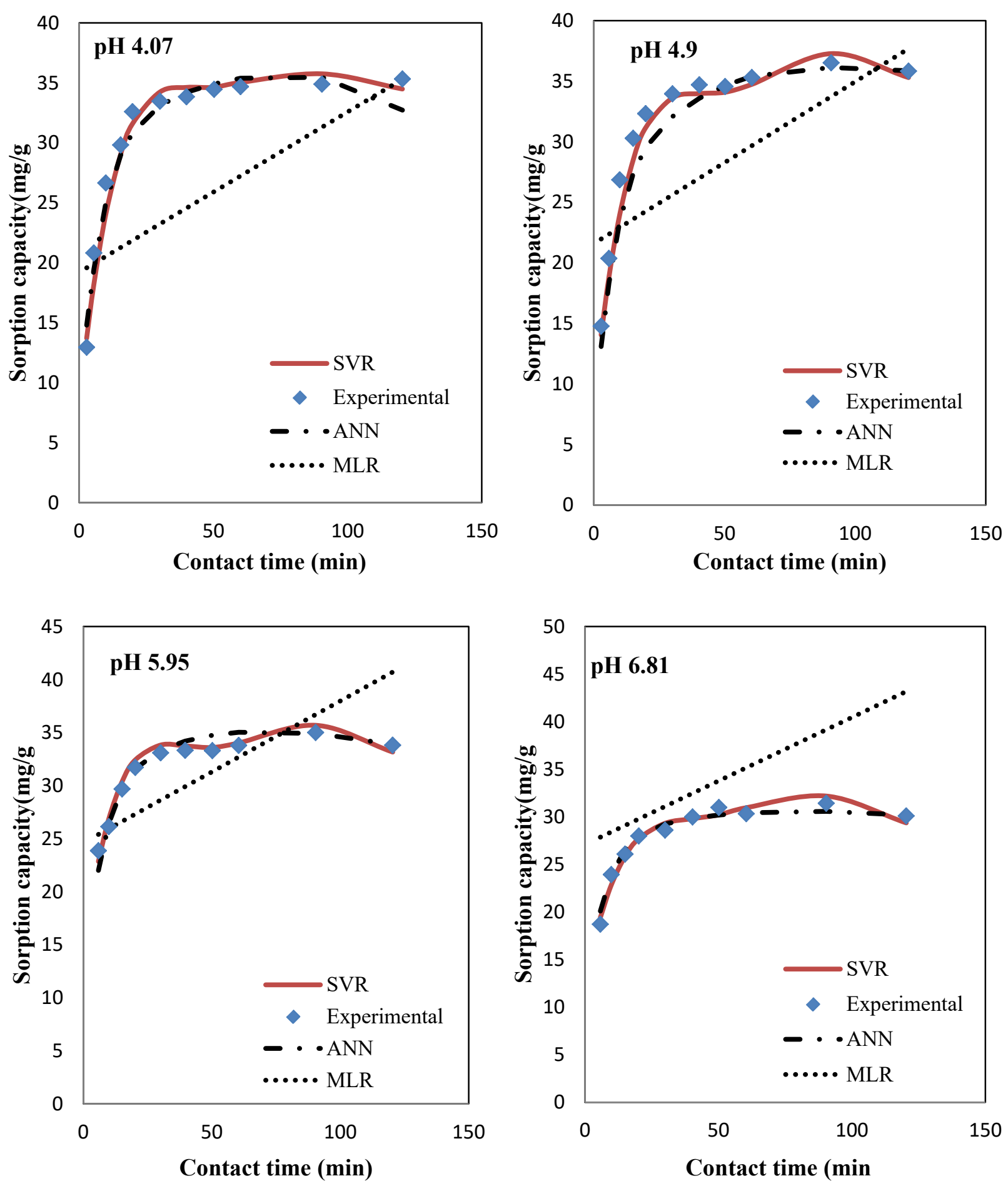

Figure 20 (a)-(e). Effect $\mathrm{pH}$ on the sorption capacity (mg/g) of lead against contact time (initial lead concentration $200 \mathrm{mg} / \mathrm{L}$, temperature $=20^{\circ} \mathrm{C}$, agitating speed $=300 \mathrm{rpm}$ ). 


\title{
4. Conclusions
}

Artificial intelligence techniques such as ANN and SVM have been applied to predict the heavy metals removal efficiency in adsorption process and the results thus obtained have been compared with those obtained by MLR. Three case studies have been studied for the removal of heavy metals like $\mathrm{Cu}$ (II), As (III) and lead (II). It has been observed that the prediction performance of SVR is the best as compared followed by ANN and MLR, in that order. It is also found that the SVR model most effectively predicts the behavior of the complex interaction process of lead (II) removal from waste water under various experimental conditions, followed by the ANN model. Good prediction results from these AI techniques can be helpful in a more efficient design and fabrication of an efficient waste water treatment plant for treating heavy metal rich effluent.

\section{Acknowledgements}

We wish to gratefully acknowledge and thank all the authors whose works have been referred to in this study, especially those whose data have been used to develop the models.

\section{Nomenclature}

$\begin{array}{ll}b & \text { Bias term } \\ C & \text { Cost function } \\ \mathrm{C}_{0} & \text { Initial Cu(II) concentration, } \mathrm{mgL}^{-1} \\ \mathrm{~F} & \text { High-dimensional feature space } \\ f(\mathbf{x}) & \text { Regression function } \\ K\left(\mathbf{x}_{i}, \mathbf{x}_{j}\right) & \text { Kernel function } \\ L & \text { Lagrangian function (dual form) } \\ \mathrm{Q}^{2} \text { ext } & \text { Leave-one-out cross validation on the test set } \\ \mathrm{Q}^{2} \mathrm{LOO} & \text { Leave-one-out cross validation on the training set } \\ \mathrm{W} & \text { Weight vector } \\ x_{i} & \text { Input vector } \\ y_{i} & \text { Output vector } \\ \mathbf{G r e e k} \text { symbols } \\ \sigma & \text { Width parameter of RBF kernel } \\ \varepsilon & \text { Loss function } \\ \gamma & \text { Regularization parameter } \\ \alpha \text { and } \alpha^{*} & \text { Lagrange multipliers } \\ \varphi\left(\boldsymbol{x}_{i}\right) & \text { Mapping function to high dimensional feature space for input vector } \mathbf{x}\end{array}$

\begin{abstract}
Abbreviations
AARE Average absolute relative error

$\mathrm{AD}$

Absolute deviation
\end{abstract}




$\begin{array}{ll}\text { ANN } & \text { Artificial neural networks } \\ \text { MSE } & \text { Mean square error } \\ \text { RMSE } & \text { Root mean square error } \\ \text { SD } & \text { Standard deviation } \\ \text { MRE } & \text { Mean relative error } \\ \text { MLR } & \text { Multiple linear regression } \\ \text { SVM } & \text { Support vector machine } \\ \text { SVR } & \text { Support vector regression }\end{array}$

\section{References}

[1] N. Das, R. Vimala, P. Karthika Biosorption of heavy metals- A review, Indian J. Biotechnol. 7 (2008) 159-169.

[2] J. Wang, C. Chen, Biosorption of heavy metals by Saccharomyces cerevisiae: A review, Biotechnol. Adv. 24 (2006) 427-451. http://dx.doi.org/10.1016/j.biotechadv.2006.03.001

[3] S. H. Abbas, I. M. Ismail, T. M. Mostafa, A. H., Sulaymon, Biosorption of Heavy Metals: A Review, J. Chem. Sci. Technol. 3 (2014) 74-102.

[4] A. Kapoor, T. Viraraghavan, Fungal biosorption- an alternative treatment option for heavy metal bearing wastewater: a review, Bioresour. Technol. 53 (1995) 185206.

[5] D. J. Sweetly, K. Sangeetha, B. Suganthi, Biosorption of Heavy Metal Lead from Aqueous Solution by Non-living Biomass of Sargassum myriocystum, International Journal of Application on Innovation in Engineering \& Management (IJAIEM) 3 (4) (2014) 39-45.

[6] V. K. Gupta, A. Nayak, S. Agarwal, Bioadsorbents for remediation of heavy metals: Current status and their future prospects, Environ. Eng. Res. 20 (2015) 118.

http://dx.doi.org/10.4491/eer.2015.018

[7] M. A. Ashraf, K. Mahmood, A. Wajid, Study of low cost biosorbent for biosorption of heavy metals, Int. Conf. Food Eng. Biotechnol. 9 (2011) 60-68.

[8] M. Zabochnicka-Świątek, M. Krzywonos, Potentials of Biosorption and Bioaccumulation Processes for Heavy Metal Removal, Pol. J. Environ. Stud. 23 (2) (2014) 551-561. 
[9] V. Eyupoglu, B. Eren, E. Dogan, Prediction of ionic Cr (VI) extraction efficiency in flat sheet supported liquid membrane using artificial neural networks (ANNs), Int. J. Environ. Res. 4(3), (2010) 463-470.

[10] Y. Vasseghian, M. F. Ahmadi, Dolati, A. Heydari, Modeling and Experimental Prediction of Wastewater Treatment Efficiency in Oil Refineries Using Activated Sludge Process, Journal of Chemical and Petroleum Engineering, 48 (1) (2014) 69-79.

[11] T. Brey, A. Jarre-Teichmann, O. Borlich, Artificial neural networks versus multiple linear regressions: predicting P/B ratios from empirical data, Mar Ecol Prog Ser. 140 (1996) 251-25. http://dx.doi.org/10.3354/meps140251

[12] K.O. Akande, T.O. Owolabi, S. Twaha, S.O. Olatunji, Performance Comparison of SVM and ANN in Predicting Compressive Strength of Concrete, IOSR Journal of Computer Engineering IOSR-JCE). 16 (5) (2014) 88-94. http://dx.doi.org/10.9790/0661-16518894

[13] A. A. Hasseim, R. P. Sudirman, I. Khalid, N. Tabatabaey-Mashadi, Comparison of ANN and SVM to Identify Children Handwriting Difficulties, Engineering 5 (2013) 1-5. http://dx.doi.org/10.4236/eng.2013.55B001

[14] A. Eskandari, R. Nouri, S.H. Meraji, A. Kiaghadi, Developing a Proper Model for Online Estimation of the 5-day Biochemical oxygen demand based on Artificial neural networks and support vector machine, Journal of Environmental Studies 38 (61) (2012) 22-24.

[15] E. A. Zanaty, Support Vector Machines (SVMs) versus Multilayer Perception (MLP) in data classification, Egyptian Informatics Journal 13, (2012) 177-183. http://dx.doi.org/10.1016/j.eij.2012.08.002

[16] U. Thissen, R. V. Brakel, A. P. D. Weijer, W.J. Melssen, L.M.C. Buydens, Using support vector machines for time series prediction, Chemometr. Intell. Lab. 69, (2003) 35- 49.

http://dx.doi.org/10.1016/S0169-7439(03)00111-4

[17] Y. Pan, J. Jiang, R. Wang, H. Cao, Y. Cui, Predicting the auto-ignition temperatures of organic compounds from molecular structure using support vector machine, J. Hazard. Mater. 164 (2009) 1242-1249.

http://dx.doi.org/10.1016/j.jhazmat.2008.09.031 
[18] Y. Radhika, M. Shashi, Atmospheric Temperature Prediction using Support Vector Machines, International Journal of Computer Theory and Engineering 1(1) (2009) 1793-8201. http://dx.doi.org/10.7763/ijcte.2009.v1.9

[19] H. Peng, X. Ling, Predicting thermal-hydraulic performances in compact heat exchangers by support vector regression, Int. J. Heat Mass Transf. 84 (2015) 203213.

http://dx.doi.org/10.1016/j.ijheatmasstransfer.2015.01.017

[20] S. Zaidi, Development of support vector regression (SVR)-based model for prediction of circulation rate in a vertical tube thermosiphon reboiler, Chem. Eng. Sci. 69 (2012) 514-521. http://dx.doi.org/10.1016/j.ces.2011.11.005

[21] S. Zaidi, Novel application of support vector machines to model the two phase boiling heat transfer coefficient in a vertical tube thermosiphon reboiler, Chem. Eng. Res. Des. 98 (2015) 44-58. http://dx.doi.org/10.1016/j.cherd.2015.04.002

[22] P. A. Webb, Introduction to Chemical Adsorption Analytical Techniques and their Applications to Catalysis, Micromeritics Instrument Corp., Norcross, Georgia, (2003)1-12.

[23] A. Buekens, N. N. Zyaykina, Adsorbents and Adsorption Processes for Pollution Control, Pollution control technologies 2 (2009) 99-123.

[24] A. Dabrowski, Adsorption - from theory to practice, Advances in Colloid and Interface Science 93 (2001) 135-224. http://dx.doi.org/10.1016/S0001-8686(00)00082-8

[25] F. I. Khan, A. K. Ghoshal, Removal of Volatile Organic Compounds from polluted air, Journal of Loss Prevention in the Process Industries 13 (2000) 527-545. http://dx.doi.org/10.1016/S0950-4230(00)00007-3

[26] J. Kipling, Adsorption from solutions of Non-Electrolytes, Academic Press. Inc., London, New York, (1965).

[27] Ju, Okoli, I. Ezuma, Adsorption Studies of Heavy Metals by Low-Cost Adsorbents, J. Appl. Sci. Environ. Manage. 18 (3) (2014) 443-448.

[28] B. Yasemin, T. Zeki, Removal of heavy metals from aqueous solution by sawdust adsorption, Journal of Environmental Sciences 19 (2007) 160-166. http://dx.doi.org/10.1016/S1001-0742(07)60026-6 
[29] C. A. Comrie, Comparing Neural Networks and Regression Models for Ozone Forecasting, J. Air \& Waste Manage. Assoc. 47 (1997) 653-663. http://dx.doi.org/10.1080/10473289.1997.10463925

[30] M. A. Doori, B. Beyrouti, Credit Scoring Model Based on Back Propagation Neural Networks Using Various Activation and Error Function. International Journal of Computer Science and Network Security (IJCSNS), 14(3) (2014) 16-24.

[31] C. -h., Kung, W. -S. Yang, C. -M. Kung, A Study on Image Quality Assessment using Neural Networks and Structure Similarty, Journal of computers, 6 (10) (2011) 2221-2228.

[32] V. Sharma, S. Rai, A. Dev, A Comprehensive Study of Artificial Neural Networks, International Journal of Advanced Research in Computer Science and Software Engineering, 2 (10) (2012) 278-284.

[33] M. Maraqa, F. Al-Zboun, M. Dhyabat, R. A. Zitar, Recognition of Arabic Sign Language (ArSL) Using Recurrent Neural Networks, Journal of Intelligent Learning Systems and Applications, 4 (2012) 41-52.

http://dx.doi.org/10.4236/jilsa.2012.41004

[34] B. Rajkumar, T. Gopikiran, S. Satyanarayana, Neural Networks Design in Cloud Computing, International Journal of Computer Trends and Technology- 4 (2) (2013) 63-67.

[35] D. K. Sonar, S. S. Gupta, Prediction and Estimation of Gyroscopic Couple by Analytical and Neural Networks, International Journal of Engineering Science Invention, 4 (6) (2015) 62-71.

[36] F. S. Panchal, M. Panchal, Review on Methods of Selecting Number of Hidden Nodes in Artificial Neural Networks, International Journal of Computer Science and Mobile Computing (IJCSMC), 3 (11) (2014) 455-464.

[37] M. Alhaz uddin, M. Jameel, H. A. Razak, Application of artificial neural networks in fixed offshore structure, Indian J. Mar. Sci. 44 (3) (2015) 1-10.

[38] A. D. Dongare, R.R. Kharde, A. D. Kachare, Introduction to Artificial Neural Networks, International Journal of Engineering and Innovative Technology (IJEIT). 2 (1), (2012)189-194.

[39] M. Madić, M. Radovanović, Methodology of developing optimal BP-ANN model for the prediction of cutting force in turning using early stopping method, Facta universitatis series: Mechanical Engineering. 9 (1) (2011) 21 - 32. 
[40] S. Mallar, R. M., T. Thyagarajan, Modelling of continuous stirred tank reactor using artificial intelligence techniques, Int. J. Simul. Model. 8 (3) (2009) 145-155. http://dx.doi.org/10.2507/IJSIMM08(3)2.128

[41] V. K. Devabhaktuni, M. C. E. Yagoub, Y. Fang, J. Xu, Q.-J. Zhang, Neural Networks for Microwave Modeling: Model Development Issues and Nonlinear Modeling Techniques, John Wiley \& Sons, Inc. (2001) 4-21.

[42] F. Musharavati, A.S.M. Hamouda, Application of artificial neural networks for modelling correlations in age hardenable aluminium alloys, Journal of achievements in materials and manufacturing engineering, 41 (2010) 140-146.

[43] R. Herbrich, Learning Kernel Classifier: Theory and Algorithm, Massachusetts Institute of Technology, MIT Press Cambridge, MA, USA (2002).

[44] S. G. Anantwar, R. Shelke, Simplified Approach of ANN: Strengths and Weakness, International Journal of Engineering and Innovative Technology (IJEIT), 1 (2012) 73-77.

[45] S. Gunn, Support Vector Machines for Classification and Regression, ISIS Technical Report, university of Southampton, (1997) 1-42.

[46] A. J. Smola, B. Scholkopf, A tutorial on support vector regression, Statistics and Computing 14 (2004) 199-222. http://dx.doi.org/10.1023/B:STCO.0000035301.49549.88

[47] W. Wang, Z. Xu, A heuristic training for support vector regression, Neurocomputing 61 (2004) $259-275$. http://dx.doi.org/10.1016/j.neucom.2003.11.012

[48] A. M. Deris, A. M. Zain, R. Sallehuddin, Overview of support vector machine in modeling machining performances, Procedia Engineering 24 (2011) 308-312. http://dx.doi.org/10.1016/j.proeng.2011.11.2647

[49] W.H. Chen, J.Y. Shih, Comparison of support-vector machines and back propagation neural networks in forecasting the six major Asian stock markets, Int. J. Electronic Finance. 1 (1) (2006) 49-67. http://dx.doi.org/10.1504/IJEF.2006.008837

[50] A. Marti, Support vector machines, IEEE Intell. Syst. 13 (1998) 18-28. http://dx.doi.org/10.1109/5254.708428

[51] G. Nalbantov, J.F. Patrick, Groenen, J. C. Bioch, Support Vector Regression Basics, Medium Econometrische Toepassingen, 13 (2005) 16-19. 
[52] K. S. Shin, T. S. Lee, H. Y. Kim, An application of support vector machines in bankruptcy prediction model, Expect Systems with Application. 28 (2005) 127135.

http://dx.doi.org/10.1016/j.eswa.2004.08.009

[53] V. Sugumaran, G.R. Sabareesh, K. I. Ramachandran, Fault diagnostics of roller bearing using kernel based neighborhood score multi-class support vector machine, Expert Systems with Applications 34 (2008) 3090-3098. http://dx.doi.org/10.1016/j.eswa.2007.06.029

[54] A.B. Gandhi, J.B. Joshi, Estimation of heat transfer coefficient in bubble column reactors using support vector regression, Chem. Eng. J. 160 (2010) 302-310. http://dx.doi.org/10.1016/j.cej.2010.03.026

[55] V.N. Vapnik, S. Golowich, A.J. Smola, Support vector method for function approximation, regression estimation and signal processing. Adv. Neural Inform. Process. Syst. 9 (1996) 281-287.

[56] C. Cortes, V. Vapnik, Support-vector networks, Machine Learning. 20 (1995) 273-297.

http://dx.doi.org/10.1007/BF00994018

[57] S. Nandi, Y. Badhe, J. Lonari, U. Sridevi, B.S. Raoc, S. S. Tambe, B. D. Kulkarni, Hybrid process modeling and optimization strategies integrating neural networks/support vector regression and genetic algorithms: study of benzene isopropylation on Hbeta catalyst, Chem. Eng. J. 97 (2004) 115-129.

http://dx.doi.org/10.1016/S1385-8947(03)00150-5

[58] R. Samant, S. Rao, A study on Comparative Performance of SVM Classifier Models with Kernel Functions in Prediction of Hypertension, International Journal of Computer Science and Information Technologies. 4 (2013) 818-821.

[59] S. X. Zhi, Z. Jian, W. B. Biao, H. D. Wei, Support vector machine approach to mean particle size of rock fragmentation due to blench blasting prediction, Trans. Nonferrous Met. Soc. China. 22 (2012) 432-441.

http://dx.doi.org/10.1016/S1003-6326(11)61195-3

[60] C. Y. Lee, S. G. Chern, Application of a Support Vector Machine for Liquefaction Assessment, J. Mar. Sci. Technol. 21 (2013) 318-324.

[61] V. Cherkassky, Y. Ma, Practical selection of SVM parameters and noise estimation for SVM regression, Neural Networks. 17 (2004) 113-126.

http://dx.doi.org/10.1016/S0893-6080(03)00169-2 
[62] M. Dundar, C. Nuhoglu, Y. Nuhoglu, Biosorption of $\mathrm{Cu}(\mathrm{II})$ ions onto the litter of natural trembling poplar forest, J. Hazard. Mater. 151 (2008) 86-95. http://dx.doi.org/10.1016/j.jhazmat.2007.05.055

[63] C. C. Chang, C. J. Lin, LIBSVM: A Library for Support Vector Machines, Department of Computer Science, National Taiwan University, Taipei, Taiwan, (2001).

[64] A.K. Giri, R.K. Patel, S.S. Mahapatra, Artificial neural networks (ANN) approach for modelling of arsenic (III) biosorption from aqueous solution by living cells of Bacillus cereus biomass, Chemical Engineering Journal 178 (2011) 15- 25. http://dx.doi.org/10.1016/j.cej.2011.09.111

[65] Y. S. Ho, W. T. Chiu, C. S. Hsu, C. T. Huang, Sorption of lead ions from aqueous solution using tree fern as a sorbent, Hydrometallurgy. 73 (2004) 55-61. http://dx.doi.org/10.1016/j.hydromet.2003.07.008

[66] Y. S. Ho, Effect of $\mathrm{pH}$ on lead removal from water using tree fern as the sorbent, Bioresour. Technol. 96 (2005)1292-1296. http://dx.doi.org/10.1016/j.biortech.2004.10.011

[67] M. Massinaei, Estimation of metallurgical parameters of flotation process from froth visual features, Int. J. Min. \& Geo-Eng. 49(1) (2015) 75-81.

[68] S. Karsoliya, Approximating Number of Hidden layer neurons in Multiple Hidden Layer BPNN Architecture, International Journal of Engineering Trends and Technology. 31 (6) (2012) 714-717.

[69] H. Merdun, Ö. Çinar, Artificial neural networks and regression techniques in modelling surface water quality, Environ. Prot. Eng. 36(2) (2010) 95-109.

[70] S. Suganthi, K. Murugesan, S. Raghavan, ANN Model of RF MEMS Lateral SPDT Switches for Millimeter Wave Applications, Journal of Microwaves, Optoelectronics and Electromagnetic Applications 11(1) (2012) 130-143. http://dx.doi.org/10.1590/S2179-10742012000100011

[71] A. Verikas, M. Bacauskiene, Using artificial neural networks for process and system modeling, Chemometr. Intell. Lab. 67 (2003) $187-191$. http://dx.doi.org/10.1016/S0169-7439(03)00093-5

[72] M. M. Joseph, O. M. Callistus, A. I. Gabriel, Application of Artificial Neural Networks For Path Loss Prediction In Urban Macrocellular Environment, American Journal of Engineering Research (AJER) 3(2) (2014) 270-275. 
[73] S. Aber, A.R. Amani-Ghadim, V. Mirzajani, Removal of Cr(VI) from polluted solutions by electrocoagulation: Modeling of experimental results using artificial neural networks, J. Hazard. Mater. 171 (2009) 484-490.

http://dx.doi.org/10.1016/j.jhazmat.2009.06.025 